\title{
ASPECTOS GEOLÓGICOS, PETROGRÁFICOS E GEOQUÍMICOS DOS MÁRMORES DOLOMÍTICOS COM NÓDULOS DE QUARTZO DA SEQUÊNCIA METAVULCANO-SEDIMENTAR DE ACARAPE-CE
}

\author{
PAULO FERNANDO MOREIRA TORRES ${ }^{1}$, CLÓVIS VAZ PARENTE ${ }^{2}$, ALCIDES NÓBREGA \\ SIAL $^{3}$, ELTON LUÍS DANTAS ${ }^{4}$, REINHARDT A. FUCK ${ }^{4}$, CÉSAR ULISSES VIEIRA \\ VERÍSSIMO $^{2} \&$ MICHEL HENRI ARTHAUD ${ }^{2}$
}

\begin{abstract}
Resumo A sequência metavulcano-sedimentar de Acarape, CE, é composta por rochas metassedimentares terrígenas neoproterozóicas, contendo intercalações de mármores, rochas calcissilicáticas e rochas metabásicas e intermediárias de natureza alcalina. O conjunto é deformado e metamorfisado em fácies anfibolito. Os mármores são lenticulares, descontínuos e estendem-se por mais de $50 \mathrm{~km}$. Em algumas pedreiras apresentam concentrações de quartzo ao longo dos planos de estratificação. Quartzo ocorre em diferentes formas: $i$ - em estruturas nodulares subesféricas; $i i$ - em camadas de espessura centimétrica e comprimento métrico; e, $i i i$ - em estruturas dobradas. Moldes e inclusões losangulares e/ou monoclínicas de sulfatos, pseudomorfoseados ou não por dolomita, em cristais de quartzo são comuns, sugerindo que a sílica é de origem diagenética e que resultou de preenchimento de vazios gerados pela dissolução de sulfato em ambiente marinho plataformal raso, sujeito a evaporação. É provável que o sulfato tenha se depositado sobre lama carbonática silicosa. Mudanças geoquímicas no ambiente de sedimentação, marcadas por variações no $\mathrm{pH}$, provocaram sua dissolução e a precipitação de quartzo, o qual foi, posteriormente, deformado. Os mármores apresentam composição calcítica-dolomítica a dolomítica, com discretas variações no campo das rochas calcissilicáticas, refletidas nos diagramas de elementos maiores $\mathrm{CaO}-\mathrm{MgO}-\mathrm{SiO}_{2}$. Parte das amostras que plotam no campo das rochas calcissilicáticas corresponde a mármores silicosos empobrecidos $\mathrm{em}_{2} \mathrm{Ol}_{3}(<1 \%), \mathrm{Na}_{2} \mathrm{O}(<0.1 \%)$ e $\mathrm{K}_{2} \mathrm{O}(<0,04 \%)$. Os elementos terras raras mostram curva irregular com modesto enriquecimento de terras raras leves em relação a pesadas e com anomalia fortemente positiva de Ce e ligeiramente positiva de Eu. Os valores de $\delta^{13} \mathrm{C}$ dos mármores são relativamente homogêneos, oscilando entre $+1,7$ e $-0,1 \%$, com uma amostra exibindo valor, excepcionalmente, baixo $(-7,6 \%)$. Os valores de $\delta^{18} \mathrm{O}_{\mathrm{smow}}$ mostram intervalo de variação entre $+18,3 \mathrm{e}+25 \%$, excepcionalmente, $+27,2 \%$. A amostra que apresenta forte variação isotópica $\left(\delta^{13} \mathrm{C}-7,6 \%\right.$ e $\delta^{18} \mathrm{O}_{\text {sMow }}{ }^{-}+27,2 \%$ ) localiza-se próxima a uma zona de carstificação recente, sujeita a modificações intempéricas. Os valores de $\delta^{13} \mathrm{C}$ das amostras melhor preservadas indicam flutuações de $\delta^{13} \mathrm{C}$ compatível com a curva de variação dos carbonatos depositados no início do Neoproterozóico.
\end{abstract}

Palavras Chave: Seqüência Acarape - CE, elementos terras raras, mármores dolomíticos, carbonatos neoproterozóicos, isótopos de ${ }^{13} \mathrm{C}$ e ${ }^{18} \mathrm{O}$.

\begin{abstract}
GEOCHEMICAL, PETROGRAPHIC AND GEOLOGICAL ASPECTS OF THE OUARTZ NODULES-BEARING DOLOMITIC MARBLES FROM THE ACARAPE-CE METAVOLCANIC-SEDIMENTARY SEQUENCE. The Acarape metavolcano-sedimentary sequence, Ceará State, Northeastern Brazil, consists of Neoproterozoic terrigenous metasedimentary rocks containing intercalations of marbles and calcsilicate rocks, as well as of metabasic and intermediate alcaline rocks. Deformation and metamorphism under amphibolite facies conditions affected the whole set. The marbles ocurr as lens-shaped, descontinuous layers that can reach more than $50 \mathrm{~km}$ and show locally (in some quarries) quartz concentration along the bedding planes. Quartz occurs as i) nodulate, subspheric structures; ii) centimetric-thick, metric-lenght beds; and iii) folded structures. Lozenge- and/or monoclinic-shaped molds and inclusions of sulfates, sometimes pseudomorphosed by dolomite in quartz crystals are common, suggesting a diagenetic origin for the silica as a result of precipitation in empty spaces generated by dissolution of sulfate in an evaporation-related, shallow-water marine environment. Deposition of the sulfate occurred probably on siliceous carbonatic mud, but later geochemical changes in the sedimentation setting, characterised by variations in the $\mathrm{pH}$ values, have caused its dissolution and quartz precipitation. The marbles present dolomitic- to calcitic-dolomitic composition, showing discreet variations inside the calcsilicate-rock field, which are reflected in the major-element diagrams $\mathrm{CaO}-\mathrm{MgO}-\mathrm{SiO}$. Some of the samples that plot in the calcsilicate-rock field correspond to siliceous marbles depleted in $\mathrm{A} 12 \mathrm{O} 3(<1 \%), \mathrm{Na} 2 \mathrm{O}(<0.1 \%)$, and $\mathrm{K} 2 \mathrm{O}(<0.04 \%)$, incompatible for calcsilicate rocks. The rare earth elements show an irregular pattern with a slight enrichment of LREE in relation to the HREE, strong positive $\mathrm{Ce}$ and moderate positive $\mathrm{Eu}$ anomalies. $\delta^{13} \mathrm{C}$ values are relatively homogeneous, ranging from +1.7 and -0.1 , whilst the $\delta^{18} \mathrm{O}_{\text {SMow }}$ values vary between +18.3 and $+25 \%$, but one of the samples, collected next to a recent carstification zone and affected by intemperic changes, shows strong isotopic fluctuation $\left(\delta^{18} \mathrm{O}_{\text {sMow }}+27.2 \%\right.$ and $\delta^{13} \mathrm{C}-7.6 \%$ ). The $\delta^{13} \mathrm{C}$ values from the best preserved samples are compatible with the carbonates isotopic curve for the beginning of the Neoproterozoic.
\end{abstract}

Keywords: Acarape - CE Sequence, rare earth elements, dolomitic marbles, neoproterozoic carbonates, ${ }^{13} \mathrm{C}$ e ${ }^{18} \mathrm{O}$ isotopes

INTRODUÇÃO A ocorrência de nódulos de sílica junto às rochas carbonáticas, embora possa parecer exótica, não é feição rara, sendo componente comum de muitas formações carbonáticas fanerozóicas. Ocorrências análogas têm sido descritas na literatura internacional como cherts nodulares formados diageneticamente a partir da substituição de sedimentos carbonáticos ou dolomíticos ou mesmo de sulfatos pré-existentes (e.g. Maliva $\&$ Siever 1989). No Brasil as referências sobre a ocorrência

\footnotetext{
1 - Dept $^{\circ}$. de Geologia UFC/CPRM, Campus Universitário do Pici, Bloco 912, CEP 60455-760, Fortaleza, Ce E-mail:ptorres@fo.cprm.gov.br

2 - Dept $^{\circ}$. de Geologia/UFC, Campus Universitário do Pici, Bloco 912, CEP 60455-760, Fortaleza,Ce. email : clovis@ufc.br

2 - Dept ${ }^{\circ}$. de Geologia/UFC, Campus Universitário do Pici, Bloco 912, CEP 60455-760, Fortaleza,Ce. email:michel.h@terra.com.br

2 - Dept ${ }^{\circ}$. de Geologia/UFC, Campus Universitário do Pici, Bloco 912, CEP 60455-760, Fortaleza,Ce.

3 - Dept ${ }^{\circ}$. de Geologia/UFPE, NEG-LABISE, Cidade Universitária, CEP 50670-000, Recife,Pe. email:sial@ufc.br

4 - Instituto de Geociências/UNB, Instituto de Geociências da UNB, 70910-900, Brasília,DF, email:elton@unb.br
} 
de nódulos de quartzo em rochas carbonáticas, particularmente em mármores, são raras ou mesmo inexistem. A origem dos nódulos, entretanto, é controvertida e duas hipóteses se destacam: uma orgânica e outra inorgânica. O modelo de origem orgânica envolve dissolução e reprecipitação de sílica biogênica (diatomáceas, radiolaritos e esponjas) por meio de atividades bacterianas durante os estágios diagenéticos iniciais (e.g. Maliva \& Siever 1989), enquanto a hipótese inorgânica admite a dissolução e reprecipitação do quartzo já existente em meio às rochas carbonáticas ou provenientes de cinzas de origem vulcânica (Friedman \& Radke 1979, Friedman \& Shukla 1980, Pollock 1987, Parente et al. 1996, Friedman 1997).

Na região estudada, os nódulos e/ou camadas centimétricas de sílica se distribuem irregularmente ao longo dos planos de estratificação de mármore dolomítico. O presente trabalho apresenta os resultados obtidos por meio de análise petrográfica e estudos litogeoquímicos nos mármores dolomíticos hospedeiros de ocorrências de quartzo da sequência metavulcano-sedimentar de Aracarape. Como principais objetivos estão o melhor entendimento dos processos de formação de sílica em meio às rochas carbonáticas pré-cambrianas e, conseqüentemente, do ambiente de deposição desta seqüência.

ASPECTOS GEOLÓGICOS A sequência metavulcanosedimentar de Acarape está localizada na porção nordeste do Domínio Ceará Central de Arthaud et al. (1998), cerca de 50km ao Sul de Fortaleza. Torres (2004), com base na natureza das associações faciológicas, dividiu esta seqüência em duas subunidades: i) A subunidade Aracoiaba, que contêm os mármores estudados, é constituída por associação metavulcano-sedimentar, dominada por rochas metassedimentares terrígenas, representadas por paragnaisses e xistos, que contêm intercalações lenticulares de quartzitos, rochas calcissilicáticas, mármores, rochas metavulcânicas e/ou metasubvulcânicas, desenvolvida em ambiente plataformal marinho raso e ; ii) A subunidade Baturité que engloba rochas metapelíticas, com alternâncias centimétricas de metapsamitos, que sugerem metarritmitos, contendo localmente intercalações decamétricas de quartzitos, anfibolitos e piroxenitos, representaria a fácies mais profunda na paleogeografia da Seqüência Acarape (Fig.1).

Os xistos e paragnaisses da subunidade Aracoiaba compõem-se de biotita, quartzo, feldspato e muscovita com ou sem granada, sillimanita (fibrolita) e grafita. Os quartzitos tendem a ocorrer próximos às bordas da subunidade na forma de corpos lenticulares ou sustentando as maiores elevações na área. Apresentam composição que varia de quartzito feldspático, por vezes com muscovita, a quartzito relativamente puro e/ou calcítico quando próximo a lentes de mármore. $\mathrm{O}$ quartzito calcítico é composto por quartzo, calcita, tremolita, epidoto, microclínio e titanita. As rochas metavulcânicas e/ou metasubvulcânicas são subordinadas e se encontram intercaladas e/ou recortando as rochas metassedimentares terrígenas e carbonáticas. São representadas por metadacitos e metatraquiandesitos. Ocorrem ainda alguns corpos metaultramáficos intrusivos representados por piroxenitos com flogopita, de afinidade alcalina, alterados a vermiculita. Datações radiométricas U-Pb em zircão de metatraquiandesito, que recorta subconcordantemente a sequência metacarbonática, revelaram idade de $642 \pm 37 \mathrm{Ma}$, interpretada como idade mínima da sedimentação carbonática (Torres et al. 2005).

ASPECTOS PETROGRÁFICOS DAS ROCHAS METACARBONÁTICAS Os mármores calcítico-dolomíticos com nódulos de sílica fazem parte da sequência metacarbonática que ocorre por mais de $50 \mathrm{~km}$ sob a forma de corpos lenticulares e descontínuos, sustentando as principais pedreiras da região, em meio às rochas metassedimentares terrígenas da subunidade Aracoiaba. A espessura dos corpos lenticulares varia de 10 a 500 metros e o comprimento pode atingir 3 quilômetros. Composicionalmente, são mármores calcítico-dolomíticos de cor branca a cinza claro, granulação média, variando de tipos relativamente puros a impuros, estes últimos contendo tremolita, diopsídio e quartzo. A sílica está distribuída irregularmente ao longo de planos de estratificação dos mármores na pedreira da Midol (Mineração Dolomita Limitada) sublinhando ou não a estratificação primária e mostra três diferentes tipologias : (i) em estruturas nodulares subesféricas, cujo eixo maior varia de 2 a $15 \mathrm{~cm}$ (Fig.2); (ii) em camadas de 1 a $4 \mathrm{~cm}$, de espessura e comprimento da ordem de centímetros a metro, como resultado provável da coalescência de nódulos (Fig.3); (iii) em estruturas dobradas, com padrões irregulares e complexos, análogos ao estilo enterolítico desenvolvido por sulfatos (anidrita) (Fig.4).

Em geral, o mármore relativamente puro compõe-se de calcita $(60 \%)$ e dolomita (38\%), e os tipos impuros contém, além dos minerais carbonáticos assinalados, tremolita, diopsídio, clorita e relíquias, provavelmente, de sulfatos. No mármore puro a textura é granoblástica poligonal. Os cristais de calcita e dolomita apresentam contatos retos e freqüentemente orientados. Os cristais de calcita, em geral geminados polissinteticamente, são deformados, com extinção ondulante e com microfraturamento. Os cristais de dolomita raramente apresentam maclas, mas encontram-se também deformados.

Nos tipos impuros, particularmente os silicosos, os cristais de quartzo, de dimensões entre alguns milímetros e $1 \mathrm{~cm}$, apresentam contornos irregulares ou suturados, mostrando reações de desequilíbrio com os carbonatos. Alguns cristais de quartzo mostram vacúolos e microinclusões losangulares e hexagonais que sugerem tratar-se, respectivamente, de pseudomorfos de sulfatos e de dolomita (Fig.5). Nos termos mais deformados, apresentam extinção ondulante, bandas de deformação e recristalização em subgrãos e mesmo cominuição nas bordas. Diopsídio ocorre como grãos anédricos ou como porfiroblastos que se desenvolvem sobretudo na interface entre os cristais de quartzo e dolomita, sublinhando uma auréola de reação metamórfica de descarbonatação (Fig. 6; reação 1). Alguns cristais de diopsídio mostram-se também deformados, com recristalização em subgrãos e parcialmente substituídos nas bordas por carbonato (calcita) e tremolita, provavelmente segundo a reação 2 :

$$
\begin{aligned}
& \text { (1) } \mathrm{CaMg}\left(\mathrm{CO}_{3}\right)_{2}+2 \mathrm{SiO}_{2}=\mathrm{CaMg} \mathrm{Si}_{2} \mathrm{O}_{6}+\underset{\text { diopsidio }}{2 \mathrm{CO}_{2}} \\
& \text { (2) } 4 \mathrm{CaMgSi}_{2} \mathrm{O}_{6}+2 \mathrm{CO}_{2}+2 \mathrm{H}^{+}+\mathrm{Mg}^{2+}=\mathrm{Ca}_{2} \mathrm{Mg}_{5} \mathrm{Si}_{8} \mathrm{O}_{22}(\mathrm{OH})_{2}+\underset{\text { tremolita }}{2 \mathrm{CaCO}_{3}}
\end{aligned}
$$

O desenvolvimento da reação (1) requer condições anidras ou quase anidras, incompatíveis para um ambiente supostamente hidrotermal. Na reação (2), em que a tremolita é formada a partir do diopsídio (uralitização), o íon de $\mathrm{Mg}^{2+}$ pode ser oriundo da decomposição da dolomita.

Os mármores impuros sem nódulos de quartzo são compostos essencialmente por calcita $(\sim 59 \%)$ e dolomita $(\sim 23 \%)$, além de tremolita $(\sim 18 \%)$ que aparece sob a forma de porfiroblastos bem desenvolvidos $(1 \mathrm{~cm})$, orientados ou ligeiramente discordantes em relação à foliação principal. Próximo às rochas metatraquiandesíticas, os cristais de tremolita aparecem também sob a forma de veios de espessura centimétrica, o que sugere que a sílica foi introduzida juntamente com fluidos aquosos ao longo de fraturas conforme a reação 3 :

(3) $5 \mathrm{CaMg}\left(\mathrm{CO}_{3}\right)_{2}+\mathrm{SiO}_{2}+\mathrm{H}_{2} \mathrm{O} \rightarrow \mathrm{Ca}_{2} \mathrm{Mg}_{5} \mathrm{Si}_{8} \mathrm{O}_{22}(\mathrm{OH})_{2}+3 \mathrm{CaCO}_{3}+7 \mathrm{CO}_{2}$ 
Fonte da Sílica e o Ambiente de Deposição A precipitação da sílica na forma de nódulos, junto às rochas carbonáticas, pode ser discutida com base em duas hipóteses, uma de origem orgânica e outra inorgânica.

Os defensores da origem biogênica baseiam-se em exemplos modernos, e advogam que a sílica proveio de dissolução de esponjas silicosas, diatomáceas e radiolaritos, depositando-se na forma de opala amorfa referida como opala A (e.g, Maliva \& Siever 1989; Tucker 1991; Chafetz \& Zhang 1998). Para vários autores, os oceanos são subsaturados em sílica, tendo em média $1 \mathrm{ppm}$ de sílica e que a causa provável dessa subsaturação seria a remoção da sílica pelos organismos supracitados, como os radiolários, diatomáceas e esponjas (e.g. Krauskopf 1956, 1959; Tucker 1991; McLane 1995). Isso, por sua vez, sugere que a água dos mares mais antigos seria mais enriquecida em sílica dissolvida que a atual, devido à inexistência desses microorganismos.

Os autores que admitem origem inorgânica consideram que a sílica estaria presente em três associações. A primeira seria como quartzo detrítico na fração areia ou silte, em uma lama carbonática sob influência evaporítica (e.g. Friedman \& Shukla 1980). A precipitação de sulfato induziria a dissolução de quartzo, devido ao aumento do $\mathrm{pH}$. Subseqüente soterramento superficial (estágio diagenético inicial) provocaria a dissolução dos cristais de sulfatos e a precipitação do quartzo, à medida que diminui o $\mathrm{pH}$. A sílica em solução, por sua vez, seria fornecida pela dissolução do quartzo detrítico, em um processo tipicamente diagenético. A solubilidade da sílica cresce com o aumento do $\mathrm{pH}$, enquanto a do carbonato diminui, de modo que a silicificação do carbonato só ocorre quando algum processo promove a diminuição do $\mathrm{pH}$. Dentre esses processos, teria-se a mistura de águas doces contendo sílica com águas marinhas intersticiais, em que a sílica é precipitada, usualmente ao longo dos planos de estratificação das rochas carbonáticas ou outros canais de permeabilidade (Knauth 1979), havendo também a oxidação de $\mathrm{H}_{2} \mathrm{~S}$ microbiológico (Clayton 1986 in Maliva \& Siever 1989). Para Knauth (1994 in Chafetz \& Zhang 1998) a silicificação ocorre durante a diagênese, antes da compactação e quando associada aos dolomitos após o começo da dolomitização. A segunda está associada a cinzas de origem vulcânica. Neste caso, a sílica seria acompanhada por teores altos em álcalis, alumínio e óxido de titânio (e.g. Pollock 1987) além de fantasmas de shards vítreos e sedimentos vulcanoclásticos associados. Na terceira, o hidrotermalismo promoveria a sílicificação, acompanhada de soluções aquosas quentes, enriquecidas em diversos metais que poderiam estar presentes em quantidades traços nestas soluções, predominantemente em forma de íons complexos. Entre estes elementos ter-se-ia $\mathrm{Na}^{+}$, $\mathrm{Ba}^{2+}, \mathrm{Ca}^{2+}, \mathrm{Mg}^{2+}, \mathrm{Sr}^{2+}$ e $\mathrm{K}^{+}$. O resultado seria a ocorrência de importantes modificações texturais e composicionais devido à interação fluido hidrotermal-rocha, levando à formação de minerais e minerais-minério, em veios e stockworks.

No presente caso, à exceção de algumas amostras de mármores que ocorrem recortadas subconcordantemente por um sill metatraquiandesítico e que apresentam concentração significativa de tremolita em forma de veios, as demais, sobretudo aquelas com nódulos de quartzo, não apresentam evidências de hidrotermalismo.

A tipologia do quartzo pode indicar que a sílica foi transportada ao local de deposição por fluidos aquosos e que os cristais de quartzo cresceram diageneticamente a partir de um substrato contendo sulfato e dolomita, como atesta a presença de moldes de sulfatos e pequenos cristais de dolomita inclusos nesses cristais. A precipitação da sílica pode ter sido favorecida : (i) pela diminuição do $\mathrm{pH}$ induzido ou por mistura de águas doces contendo sílica com águas marinhas, como sugerido por Knauth (1979); ii) a partir de reações bioquímicas, onde os sulfatos são reduzidos por atividade bacteriana conforme a reação $2 \mathrm{CH}_{2} \mathrm{O}+$

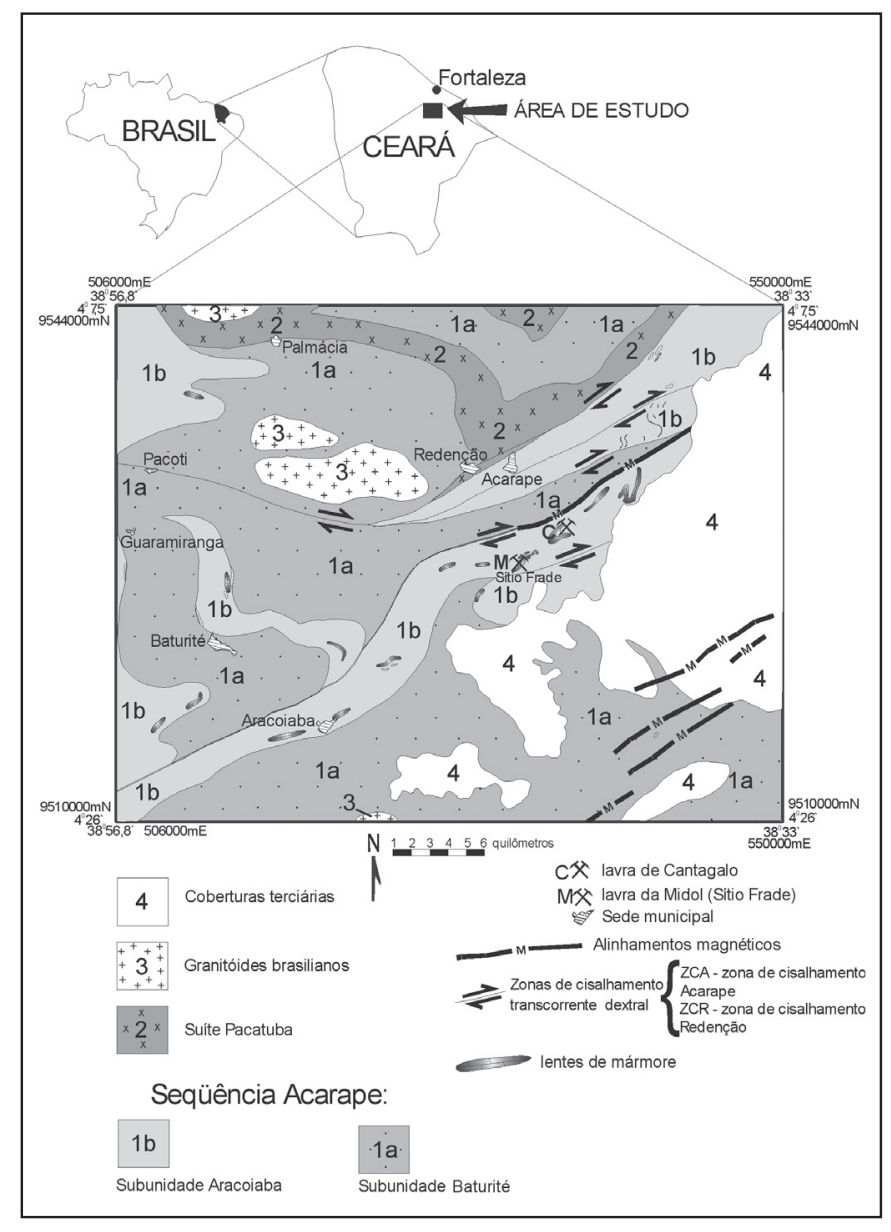

Figura 1 - Esboço geológico da Sequência Acarape

$\mathrm{SO}_{4}^{2-}=2 \mathrm{HCO}_{3}+\mathrm{HS}^{-}+\mathrm{H}^{+}$. Isso eleva a produção dos ácidos orgânicos junto com aqueles de $\mathrm{H}_{2} \mathrm{~S}$ e $\mathrm{CO}_{2}$ fazendo baixar o $\mathrm{pH}$. O resultado é o aumento da dissolução do carbonato acompanhado da precipitação da sílica.

Embora cherts nodulares modernos sejam em geral formados por substituição diagenética de calcários fósseis ou oóides, típicos de ambientes de águas superficiais, nos nódulos observados não existem traços ou remanescentes de microorganismos que indiquem que a sílica é de origem biogênica, de modo que a fonte mais provável para a sílica é inorgânica, sendo sua precipitação favorecida em função da variação do $\mathrm{pH}$.

A presença de nódulos de quartzo em meio às rochas carbonáticas estudadas sugere uma seqüência carbonática-evaporítica que se acumulou em um sistema complexo de sabkha-plataformal, marcado por uma sucessão de ambientes de submaré a supramaré.

Nas regiões de supramaré, sujeitas à exposição subaérea, em que se concentraram os nódulos evaporíticos, os carbonatos foram passíveis de circulação de águas meteóricas enriquecidas em sílica, resultado provavelmente do abaixamento do nível do mar. Isso favoreceu também a dissolução de sulfatos, uma vez que são muito mais solúveis na presença de água doce que os carbonatos.

GEOQUÍMICA DOS ELEMENTOS MAIORES MENORES E TERRAS RARAS As rochas metacarbonáticas (vinte e cinco amostras) foram analisadas no LAKEFIELD -GEOSOL para elementos maiores, menores e traços. $\mathrm{SiO}_{2}, \mathrm{Al}_{2} \mathrm{O}_{3}$, Fe-total, $\mathrm{CaO}, \mathrm{MgO}, \mathrm{MnO}, \mathrm{P}_{2} \mathrm{O}_{5}$ e TiO 2 foram determinadas por Fluorescência de Raios $\mathrm{X}$ em amostras fundidas com $\mathrm{Li}_{2} \mathrm{~B}_{4} \mathrm{O}_{7}$. 


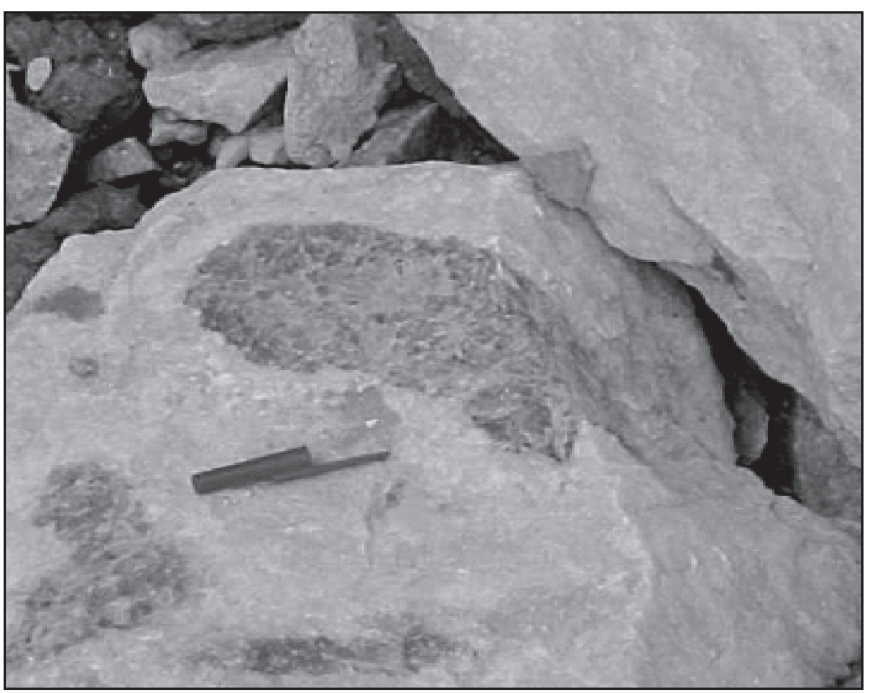

Figura 2 - Nódulos de quartzo subesférico em meio aos mármores dolomíticos. Pedreira da Midol.

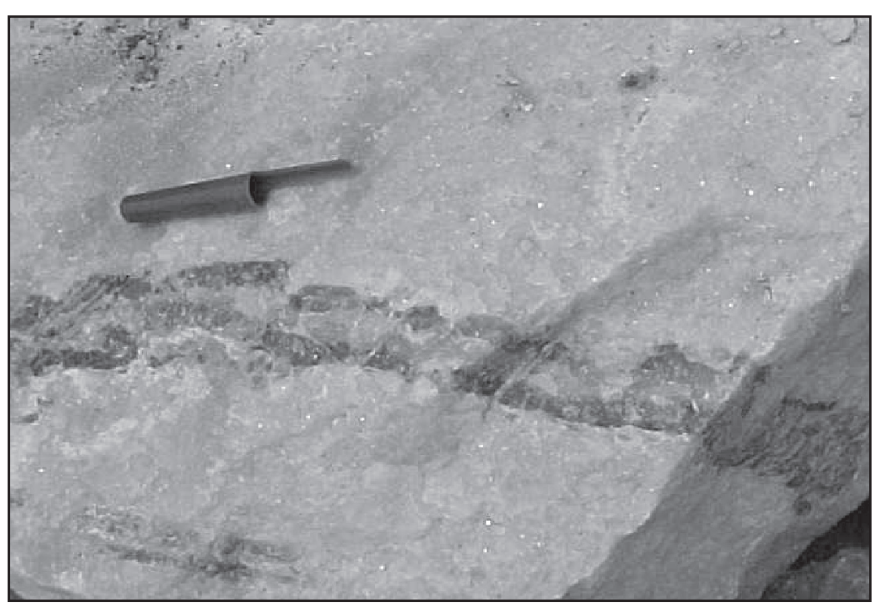

Figura 3- Camadas de sílica com espessura da ordem de 4cm, e comprimento métrico, resultado provavelmente da coalescência dos nódulos. Pedreira da Midol.

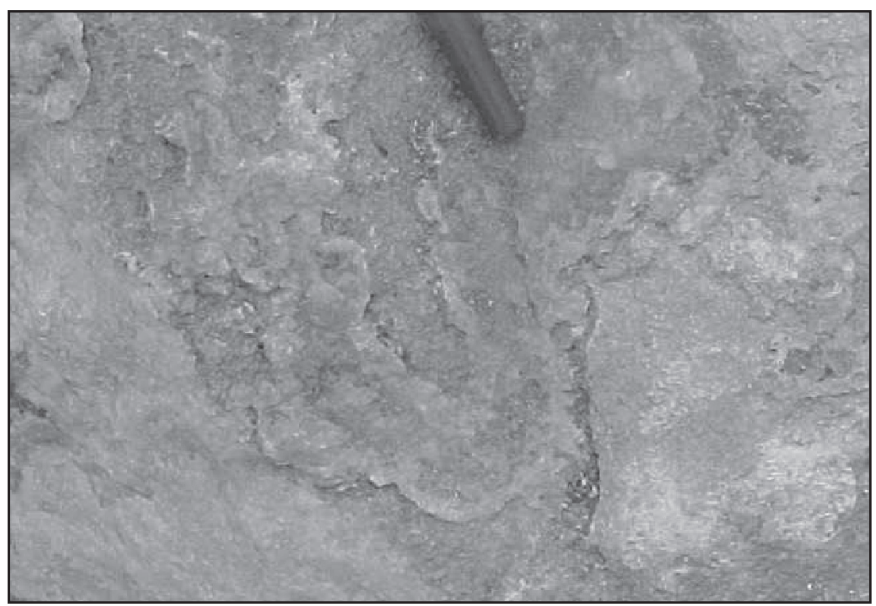

Figura 4 - Leitos de quartzo com estruturas dobradas, mostrando padrões irregulares e complexos, que lembram o estilo enterolítico desenvolvido por sulfatos (anidrita). Pedreira da Midol.

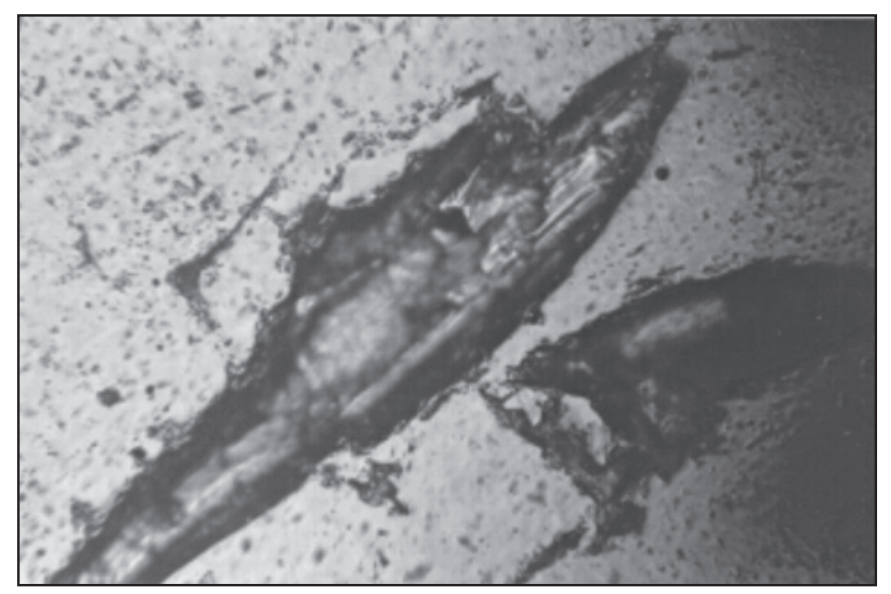

Figura 5- Microinclusões losangulares de dolomita em megacristais de quartzo sugerindo a presença de pseudomorfos de sulfatos. Nicóis //; aumento 40X.

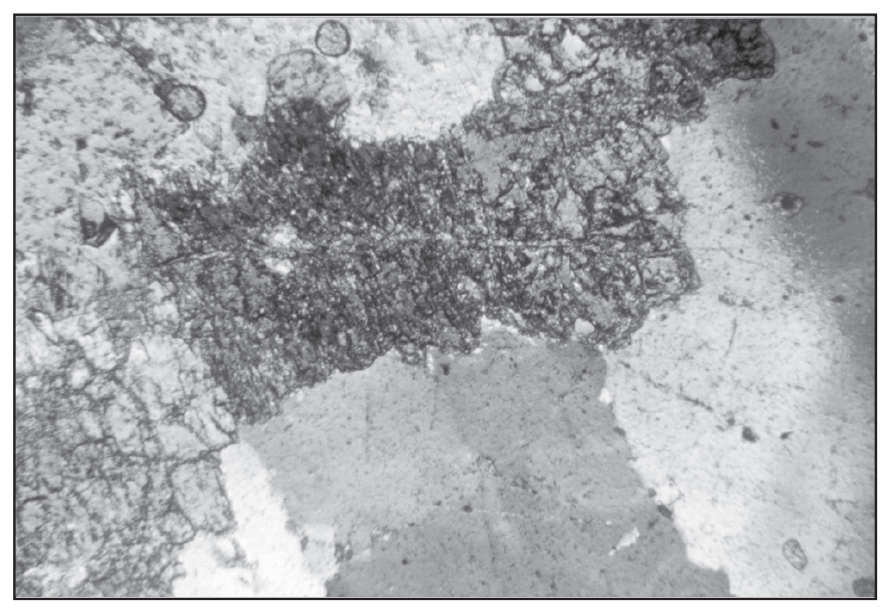

Figura 6- Agregados de diopsídio formados a partir da reação quartzo + dolomita Nicóis Cruzados; aumento 10X. dp-diopsídio, do-dolomita, qz- quartzo

$\mathrm{FeO}$ foi analisado através de decomposição por $\mathrm{HF}+\mathrm{H}_{2} \mathrm{SO}_{4} \mathrm{em}$ cadinho de platina tampado com liberação de $\mathrm{CO}_{2}$ e titulação com $\mathrm{KMnO}_{4}$ em presença de ácido bórico. Os Elementos Terras Raras (ETRs) foram determinados por ICP 3500 da ARL.

Do total de amostras, 16 representam mármores calcíticodolomíticos da principal pedreira da Midol, sendo 14 coletadas segundo um intervalo regular, de aproximadamente três metros (amostras PT-34A a PT-34O) e 2 (PT-35A e PT-35B), coletadas em outro corpo, 50 metros depois. Outras quatro amostras representam mármores calcítico-dolomíticos com nódulos silicosos coletados na mesma pedreira (PT-34A`, PT-36', PT-37`A e PT37'B, esta última próxima a uma brecha de dissolução cárstica recente). Das amostras restantes, 3 (PT-43D, PT-43D e PT-43E) foram coletadas em mármores calcítico-dolomíticos da pedreira Cantagalo, recortados subconcordantemente por um corpo de metatraquiandesito, com espessura variando de 5 a 20 metros, assemelhando-se a sill, localizado a cerca de $2,5 \mathrm{Km}$ a nordeste da pedreira da Midol, 1 (PT-23C), foi coletada na localidade de Morro Preto, no alto da Serra do Cantagalo, cerca de $4 \mathrm{~km} \mathrm{a}$ nordeste da pedreira Cantagalo e 1 (PT-22B), correspondendo a pequenos blocos de mármore, com tons azulados, foi amostrada junto a blocos de rochas metaultramáficas, nas proximidades da localidade de Pau Branco, cerca de 4,5 km a norte-nordeste da 


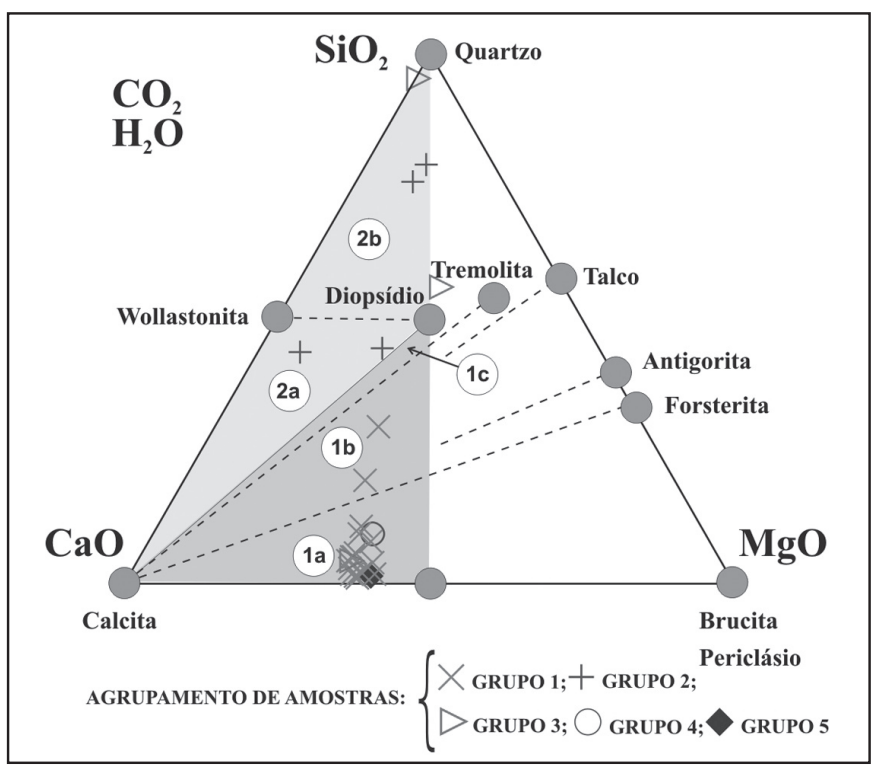

Figura 7: Diagrama $\mathrm{SiO}_{2}-\mathrm{CaO}-\mathrm{MgO}$ (Bucher \& Frey 1994). Campos 1a, 1b e 1c: mármores dolomíticos a calcítico-dolomíticos. Campos 2a e 2b: mármores calcissilicáticos.

pedreira Cantagalo (Tabelas 1 e 2 ).

Comportamento dos elementos maiores nos mármores A maioria das amostras das rochas carbonáticas está posicionada no campo dos mármores calcítico-dolomíticos e dolomíticos (Fig. 7), enquanto seis amostras se situam no campo das rochas calcissilicáticas (grupos 2 e 3) que correspondem aos mármores mais silicosos e em contato com o sill metatraquiandesítico, respectivamente. Entretanto, as rochas correspondentes aos mármores silicosos são extremamente empobrecidas em $\mathrm{Al}_{2} \mathrm{O}_{3}$ $(<1 \%), \mathrm{Na}_{2} \mathrm{O}(<0.1 \%)$ e $\mathrm{K}_{2} \mathrm{O}(<0,04 \%)$, fato incompatível para rochas calcissilicáticas, que normalmente contêm percentuais significativos desses componentes químicos e apresentam composição mineralógica muito mais complexa.

No diagrama triangular $\mathrm{Fe}_{2} \mathrm{O}_{3}-\mathrm{CaO}-\mathrm{MgO}$ (Deer et al. 1962) (Fig. 8), as amostras estudadas plotam preferencialmente nos campos dos mármores calcítico-dolomíticos e dolomíticos, exceto uma delas (grupo 3), que se desloca em direção ao vértice $\mathrm{Fe}_{2} \mathrm{O}_{3}$ (campo da ankerita). Trata-se da amostra PT-43E, com $15 \%$ de tremolita, que contém algum $\mathrm{Fe}^{2+}$ substituindo ionicamente magnésio (e.g.Dana 1983), o que explicaria, em parte, o deslocamento no sentido do vértice FeOt.

No geral, os mármores calcítico-dolomíticos mostram valores de $\mathrm{SiO}_{2}$ inferiores a 5,4\%, à exceção das rochas silicosas, que revelam teores de $\mathrm{SiO}_{2}$ entre 12,6 e 78,9 \% (Tabela 1). Os teores de $\mathrm{MgO}$ situam-se entre 19,3 e $24 \%$, os de $\mathrm{CaO}$ entre 30 e $35,5 \%$, e os de $\mathrm{Fe}_{2} \mathrm{O}_{3}$ entre 0,08 e $0,93 \%$. O conteúdo de $\mathrm{Al}_{2} \mathrm{O}_{3}$ é muito baixo $(<1,1 \%)$, assim como os valores de $\mathrm{Na}_{2} \mathrm{O}(<0.1 \%)$ e $\mathrm{K}_{2} \mathrm{O}(<0,04 \%)$. MnO é inferior a 0,4 e $\mathrm{P}_{2} \mathrm{O}_{5}$ apresenta teores menores que 1,1\%. À exceção da amostra PT- PT-43D1 (0,3\%), $\mathrm{TiO}_{2}$ apresenta valores em geral abaixo do limite de detecção $(<0,01)$. O mesmo ocorre com $\mathrm{Sr}, \mathrm{Ba}, \mathrm{F}$ e $\mathrm{Cl}$, sendo a única exceção a amostra PT-43D $(\mathrm{Sr}=104, \mathrm{Ba}=52, \mathrm{Cl}=57, \mathrm{~F}=$ 3015 ppm).

Os elementos variam também conjuntamente. Nos mármores calcítico-dolomíticos, o $\mathrm{CaO}$ mostra correlação positiva com $\mathrm{MgO}$ (Fig. 9), o que é explicado pela presença de dolomita nos grupos estudados. O CaO exibe também forte correlação negativa com $\mathrm{SiO}_{2}$ (amostras do grupo 2 e 3) (Fig.10), indicando que grande parte da sílica está na fase livre (quartzo) e não na forma

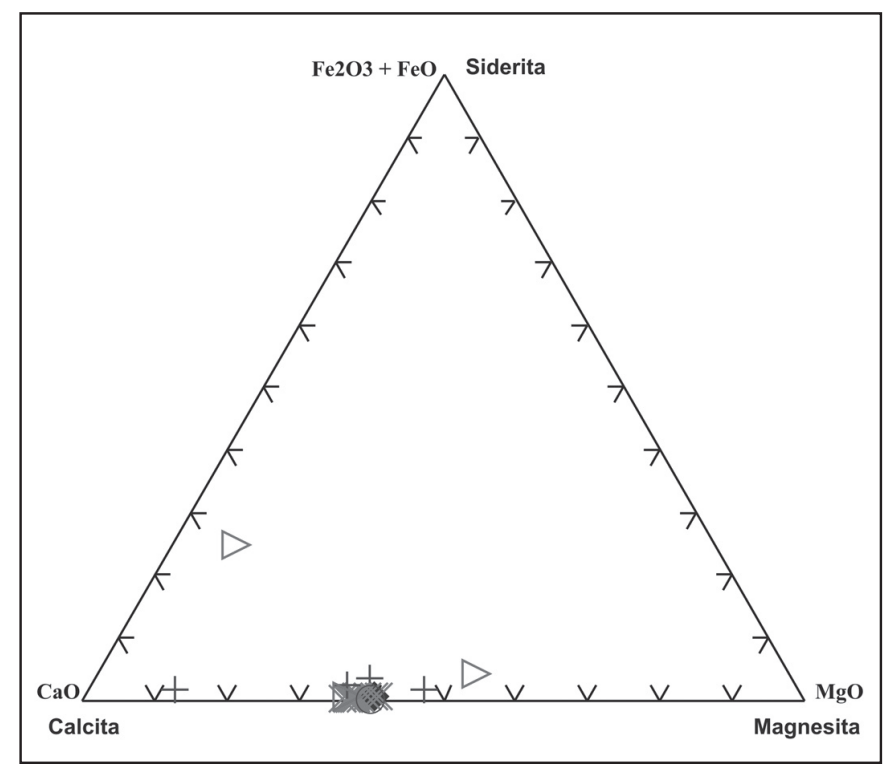

Figura 8: Diagrama $\mathrm{Fe}_{2} \mathrm{O}_{3}+\mathrm{FeO}-\mathrm{CaO}-\mathrm{MgO}$ (Deer et al. 1962) dos mármores da área. Os símbolos são os mesmos da figura 7.

combinada (tremolita e/ou diopsídio). $\mathrm{SiO}_{2}$ apresenta também correlação negativa com $\mathrm{MgO}$ e, à exceção de duas amostras que mostram correlação positiva com $\mathrm{Al}_{2} \mathrm{O}_{3}\left(\mathrm{PT}-43 \mathrm{D}_{1}\right.$ e PT$43 \mathrm{E})$ e contêm flogopita, as demais apresentam fraca correlação com $\mathrm{Al}_{2} \mathrm{O}_{3}$ (Fig. 11), indicando que a sílica é em grande parte encontrada em fase livre. A maioria das amostras contém valores de $\mathrm{MnO}$ abaixo do limite de detecção. $\mathrm{Fe}_{2} \mathrm{O}_{3}$ mostra correlação positiva com $\mathrm{Al}_{2} \mathrm{O}_{3}$ em algumas amostras, principalmente aquelas do grupo 3. Uma explicação possível é a existência de flogopita nessas rochas, na qual $\mathrm{Mg}$ pode ser substituído por $\mathrm{Fe}^{2+}$ (Dana 1983). Quanto aos possíveis minerais alumino-silicáticos esboçados no diagrama $\mathrm{Fe}_{2} \mathrm{O}_{3}+\mathrm{FeO}-\mathrm{Al}_{2} \mathrm{O}_{3}$ (Fig.12), constata-se que a maioria das amostras apresenta teores variáveis de $\mathrm{Fe}_{2} \mathrm{O}_{3}+\mathrm{FeO}$, com pequenas variações de $\mathrm{Al}_{2} \mathrm{O}_{3}$, indo do campo da caolinita até o campo da clorita. Uma pequena proporção de amostras exibe valores consideráveis de $\mathrm{Al}_{2} \mathrm{O}_{3}$. Valores altos de $\mathrm{Fe}_{2} \mathrm{O}_{3}+\mathrm{FeO}$ e $\mathrm{Al}_{2} \mathrm{O}_{3}$ são apresentados por duas amostras do grupo 3, provavelmente decorrente da presença de variedades mais ferrosas de flogopita.

A comparação entre $\mathrm{SiO}_{2}$ e $\mathrm{Na}_{2} \mathrm{O}, \mathrm{K}_{2} \mathrm{O}, \mathrm{Sr}$, $\mathrm{Ba}$ e Cl, em diagramas não representados, não mostra qualquer correlação entre este conjunto de elementos, de modo que os baixos valores desses elementos indicam que a silicificação não foi produto de hidrotermalismo.

Comportamento dos elementos terras raras nos mármores Das 25 amostras de mármores, 10 foram selecionadas para determinação de Elementos Terras Raras (Tabela 2), assim distribuídas: uma do grupo 4, uma do grupo 5, quatro do grupo 1 , uma do grupo 2 e três do grupo 3 .

No geral, os mármores estudados apresentam $\Sigma$ ETR entre 8,88 a 31,35 ppm. A razão $(\mathrm{La} / \mathrm{Lu}) n$ varia de 1,75 a 22,76 , sendo os menores valores associados às amostras PT-22B e PT-23C (grupos 4 e 5) e o maior valor (PT-43D1, grupo 3) ao mármore recortado pelo sill metatraquiandesitico.

Ao normalizar as amostras estudadas com o folhelho NASC (Haskin et al. 1968) (Fig. 13), observa-se forte anomalia positiva de $\mathrm{Ce}$ e $\mathrm{Eu}$ em quase todas as amostras. Essas anomalias (assim como os valores de todos os elementos associados) posicionam-se abaixo da razão 1 do padrão folhelho, sugerindo que a concentração desses elementos, particularmente do Eu, não 


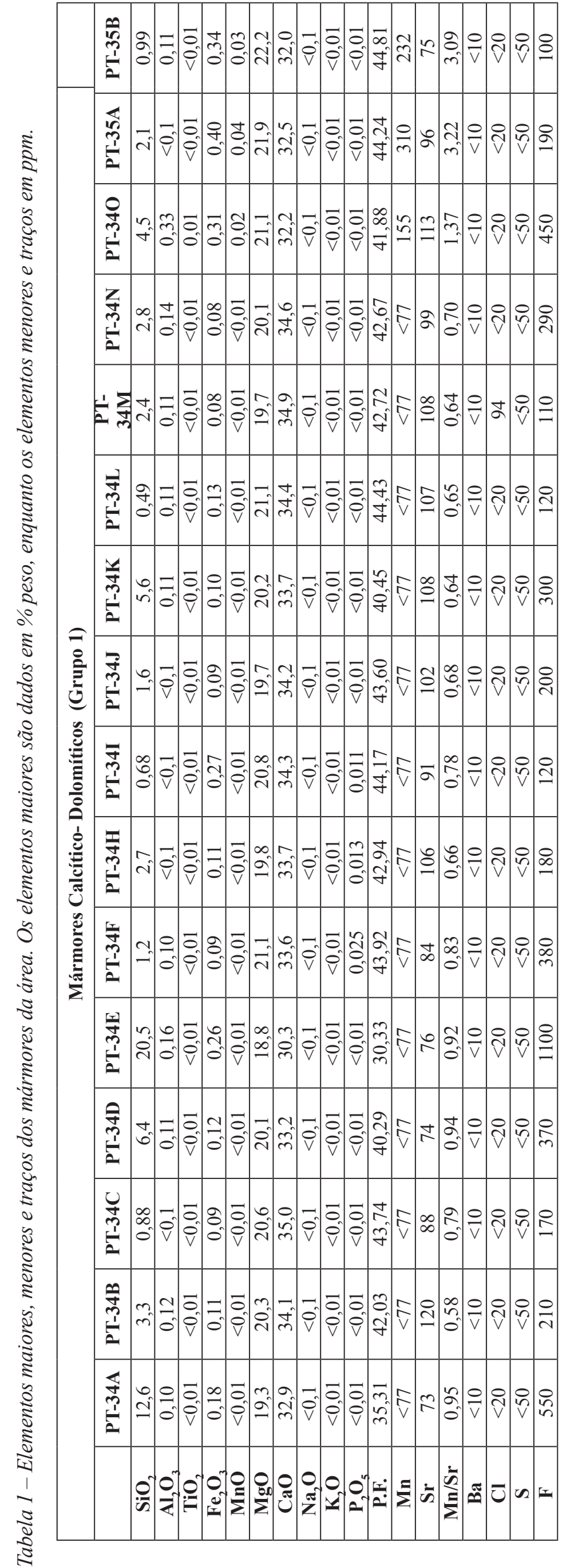

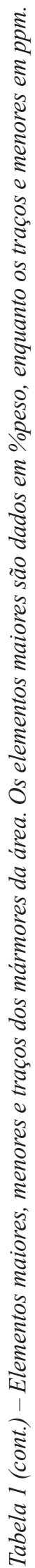




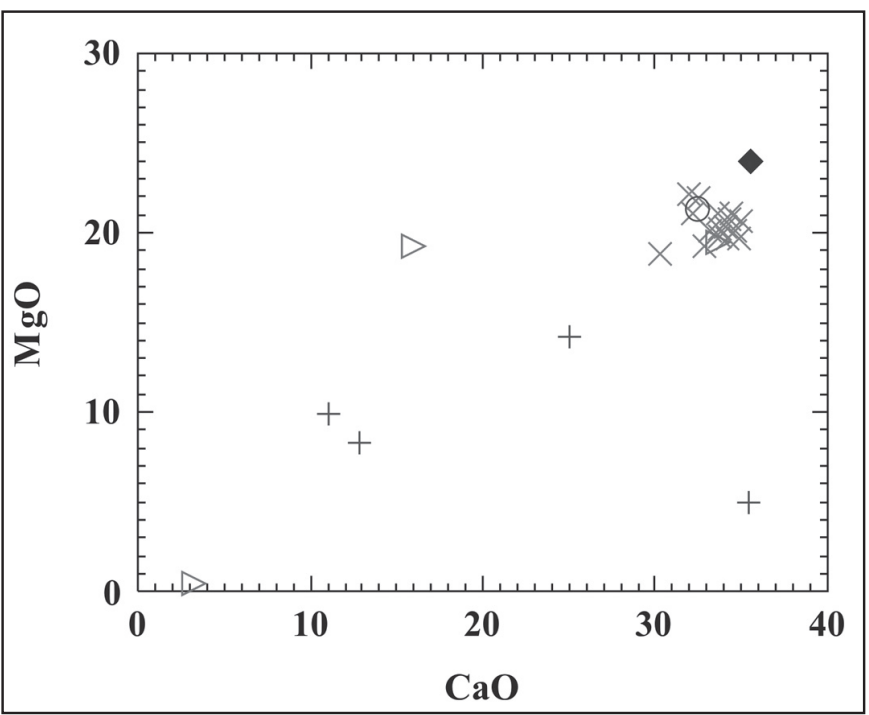

Figura 9: Diagrama CaO-MgO dos mármores da área. Os símbolos são os mesmos da figura 7.

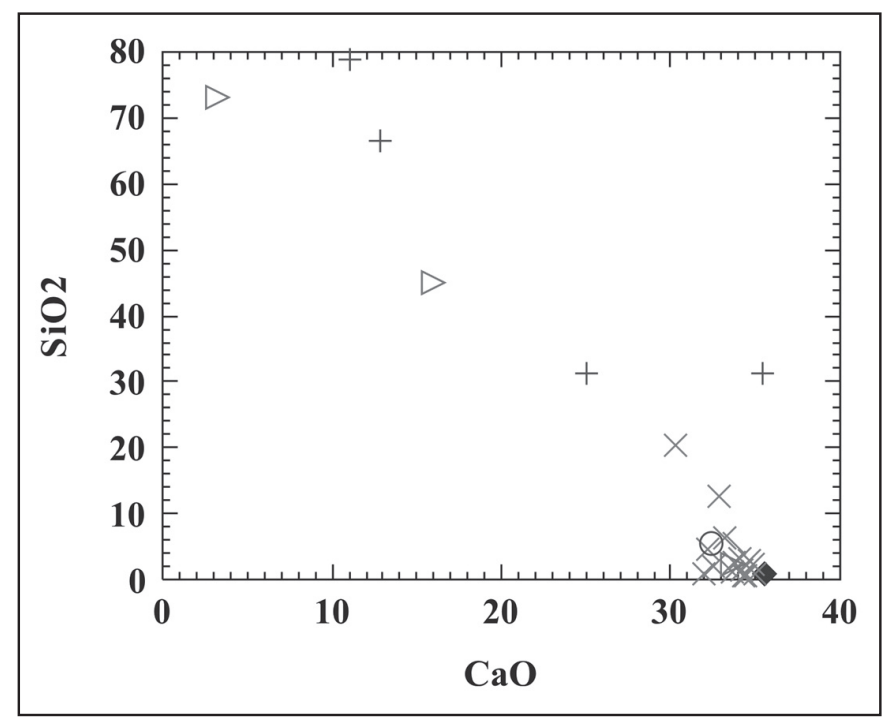

Figura 10: Diagrama $\mathrm{SiO}_{2}$-CaOdos mármores da área. Os símbolos são os mesmos da figura 7.

Tabela 2 - Elementos Terras Raras dos mármores da área.

\begin{tabular}{|c|c|c|c|c|c|c|c|c|c|c|}
\hline \multicolumn{4}{|c|}{ GRUPO 1 } & GRUPO 2 & \multicolumn{3}{|c|}{ GRUPO 3 } & GRUPO 4 & \multicolumn{2}{c|}{ GRUPO 5 } \\
\hline $\mathbf{p p m}$ & PT-34D & PT-34J & PT-34O & PT-35A & PT-36 & PT-43D1 & PT-43D2 & PT-43E & PT-23C & PT-22B \\
\hline La & 1,22 & 0,60 & 4,05 & 1,59 & 1,05 & 6,36 & 2,71 & 2,55 & $<0,5$ & $<0,5$ \\
\hline Ce & 13,0 & 7,2 & 25,2 & 15,4 & 12,1 & 15,4 & 18,0 & 17,5 & 9,9 & 9,8 \\
\hline Nd & $<0,5$ & $<0,5$ & 1,4 & $<0,5$ & $<0,5$ & 0,05 & 1,3 & $<0,5$ & $<0,5$ & $<0,5$ \\
\hline Sm & $<0,1$ & $<0,1$ & $<0,1$ & $<0,1$ & $<0,1$ & 0,74 & $<0,1$ & 0,18 & $<0,1$ & $<0,1$ \\
\hline Eu & $<0,05$ & $<0,05$ & $<0,05$ & $<0,05$ & $<0,05$ & 0,16 & 0,06 & 0,20 & $<0,05$ & $<0,05$ \\
\hline Gd & $<0,2$ & $<0,2$ & 0,22 & $<0,2$ & $<0,2$ & 0,72 & $<0,2$ & 0,35 & $<0,2$ & $<0,2$ \\
\hline Dy & $<0,1$ & $<0,1$ & $<0,1$ & $<0,1$ & $<0,1$ & 0,52 & 0,11 & 0,13 & $<0,1$ & $<0,1$ \\
\hline Ho & $<0,05$ & $<0,05$ & $<0,05$ & $<0,05$ & $<0,05$ & $<0,05$ & $<0,05$ & $<0,05$ & $<0,05$ & $<0,05$ \\
\hline Er & $<0,05$ & $<0,05$ & $<0,05$ & $<0,05$ & $<0,05$ & 0,11 & 0,13 & $<0,05$ & $<0,05$ & $<0,05$ \\
\hline Yb & 0,10 & $<0,05$ & 0,11 & 0,12 & 0,07 & 0,16 & 0,08 & 0,06 & $<0,05$ & $<0,05$ \\
\hline Lu & $<0,03$ & $<0,03$ & 0,04 & $<0,03$ & $<0,03$ & $<0,03$ & $<0,03$ & $<0,03$ & 0,03 & $<0,03$ \\
\hline La/Lu & 4,36 & 2,14 & 10,51 & 5,69 & 3,75 & 22,76 & 9,70 & 4,41 & 1,75 & 1,75 \\
\hline Ce/La & 10,65 & 12 & 6,22 & 9,68 & 11,52 & 2,42 & 6,64 & 6,86 & 20,2 & 20 \\
\hline EETR & 15,36 & 8,88 & 31,35 & 18,15 & 14,26 & 24,30 & 22,75 & 21,62 & 11,47 & 11,38 \\
\hline
\end{tabular}

foi influenciada por processos hidrotermais associados a rochas ígneas, podendo estar ligada, predominantemente, a processos deposicionais ou diagenéticos.

Comportamento semelhante ao anterior é observado ao normalizar os resultados dessas amostras com o padrão da água do mar atual (Figura 14). Merece destaque a pronunciada anomalia positiva de Ce em todas amostras analisadas, igual ou superior a três vezes o valor do padrão. Todas as amostras também exibem anomalias positivas de Eu.

Anomalias de Ce e Eu O comportamento dos ETRs na água do mar é controlado por vários fatores, entre os quais influxo hidrotermal marinho e/ou intempérico, processos de remoção relacionados à profundidade, à salinidade e níveis de oxigenação marinhos (Elderfield 1988, Holser 1997, Van Kranendonk et al. 2003, Nothdurft et al. 2004). Os comportamentos dos elementos $\mathrm{Ce}$ e Eu têm sido de grande utilidade na reconstituição paleoambiental, pois variam em função das condições de oxidação-redução encontradas em ambiente sedimentar e/ou oceânico. Alguns autores admitem que os sedimentos marinhos são empobrecidos em Ce e consideram que esta redução, em águas oceânicas modernas, está associada à incorporação preferencial de $\mathrm{Ce}^{4+}$ em minerais autigênicos, tais como nódulos de $\mathrm{Mn}$ e fosforitos (e.g. Piper 1974, McLennant et al. 1979). Deste modo, o fracionamento de Ce em relação aos outros ETR está associado à sua remoção mais fácil na presença de oxigênio. Nos oceanos, $\mathrm{Ce}^{3+}$ é oxidado para $\mathrm{Ce}^{4+}$, insolúvel, que se precipita como $\mathrm{CeO}_{2}$, resultando em empobrecimento desse elemento na água 


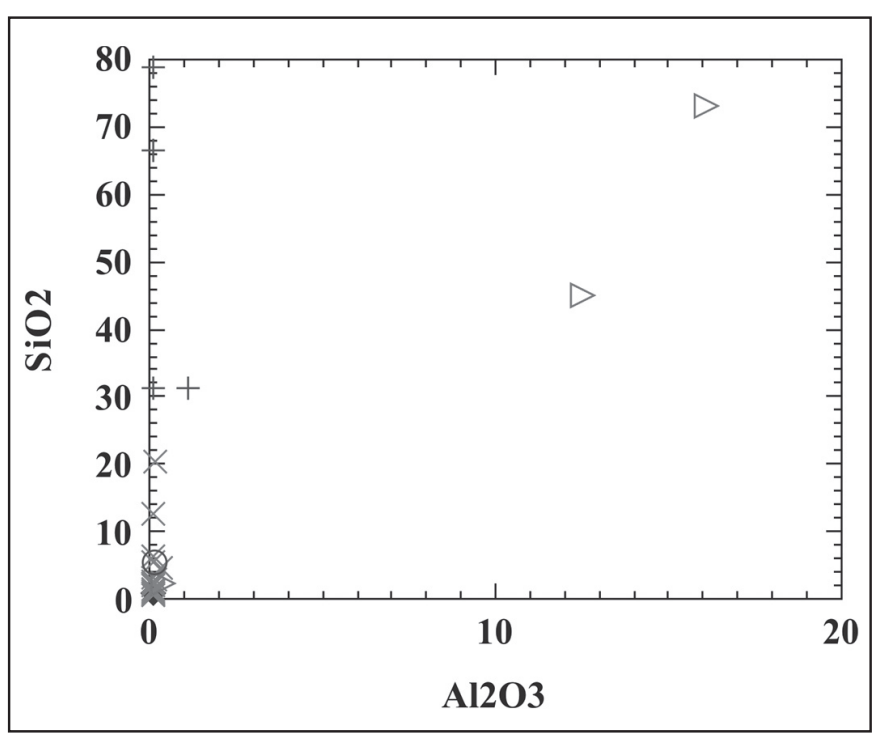

Figura 11: Diagrama $\mathrm{SiO}_{2}-\mathrm{Al}_{2} \mathrm{O}_{3}$ dos mármores da área. Os símbolos são os mesmos da figura 7.

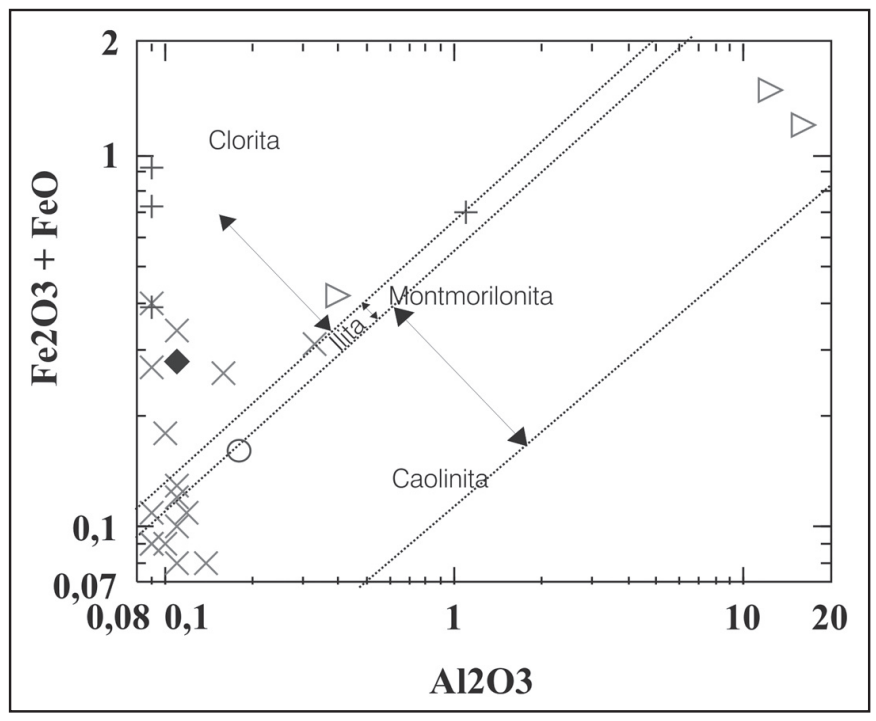

Figura 12: Diagrama $\mathrm{Fe}_{2} \mathrm{O}_{3}+\mathrm{FeO}-\mathrm{Al}_{2} \mathrm{O}_{3}$ dos mármores da área. Os símbolos são os mesmos da figura 7 .

do mar em relação aos outros ETR. Para Wilde et al. (1996) a anomalia de Ce pode ser usada como indicador das variações eustáticas do nível do mar. Anomalias positivas indicariam condições oxidantes, associadas às fases regressivas marcadas pelo abaixamento do nível do mar, enquanto as anomalias negativas estariam relacionadas à fase transgressiva representada pela elevação do nível do mar, na qual as águas do fundo tornar-se-iam mais anóxicas. Entretanto, tem-se verificado que, em ambientes estuarinos, Ce não é removido em solução. Sob condições suficientemente oxidantes, Ce é removido no estágio inicial, juntamente com óxidos de Fe nas águas fluviais. Em locais nos quais tais complexos óxido-hidróxido foram preservados, como por exemplo em sedimentos carbonáticos estuarinos devonianos, estes mostram anomalia positiva de Ce. Martim et al. (1976 in Fleet 1984), ao estudarem o Estuário Gironda, verificaram que a razão $\mathrm{Ce} / \mathrm{La}$ permanece constante, indicando que Ce não é removido em solução em ambientes estuarinos. Amostras de água do Mar Barents (Hogdahl et al. 1968 in Fleet 1984), também

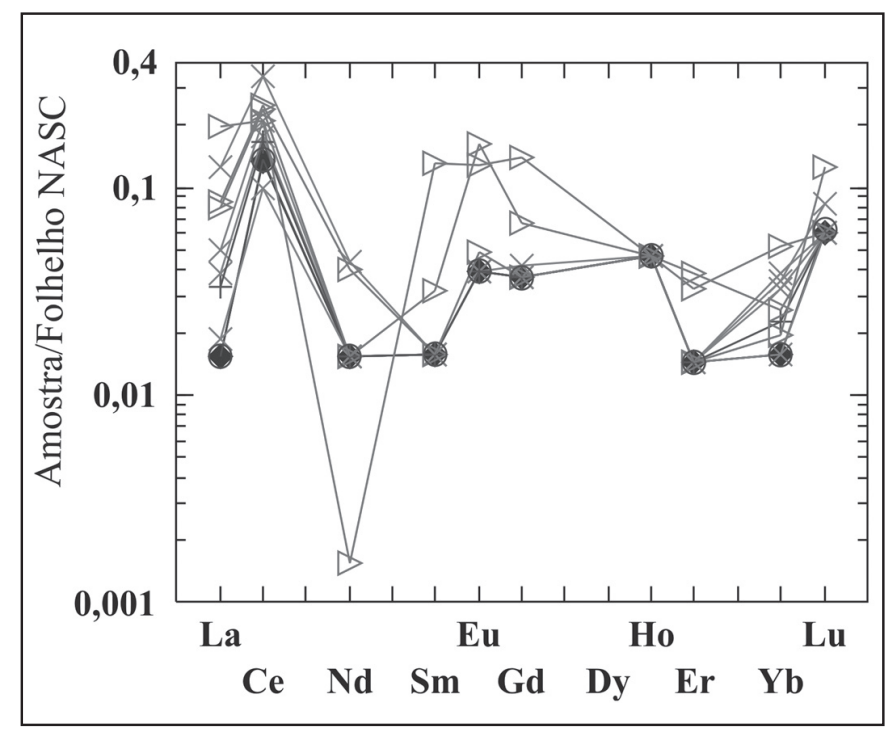

Figura 13: padrão dos ETRs dos mármores da área normalizado ao folhelho NASC (Haskin et al. 1968). Os símbolos são os mesmos da figura 7 .

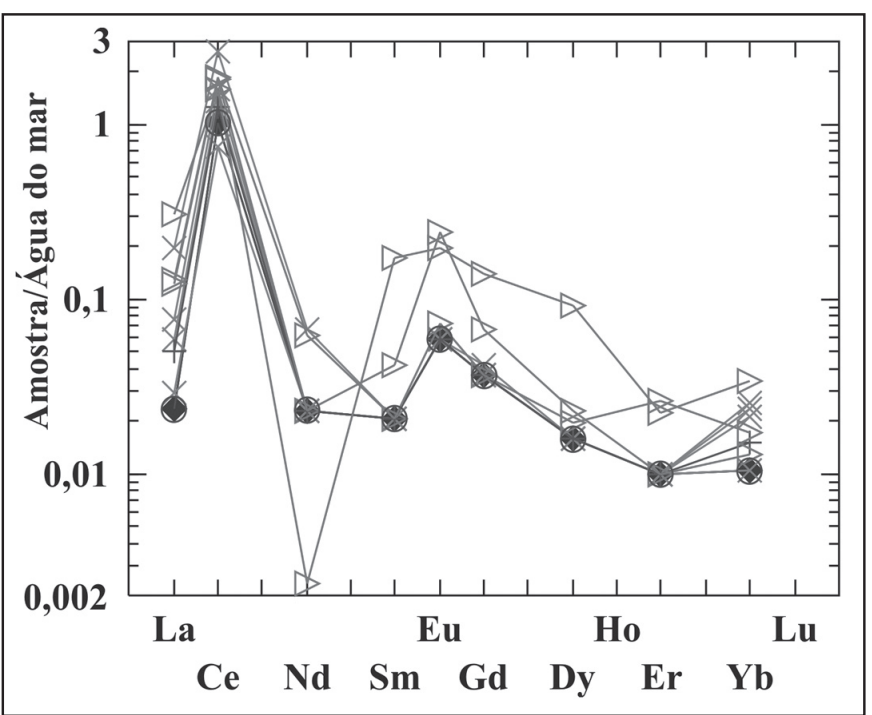

Figura 14: padrão dos ETRs dos mármores da área normalizado em relação a água do mar. Os símbolos são os mesmos da figura 7.

não exibem anomalias negativas de Ce e a água próxima à costa leste dos EUA é 10 a 100 vezes mais rica em Ce que a amostra do Oceano Atlântico adjacente. Amostras de cherts depositados em extensas plataformas também não mostram anomalias negativas de Ce (Fleet 1984). Essas considerações implicam que as anomalias positivas de Ce observadas em sedimentos carbonáticos podem indicar a presença de ambiente estuarino ou marinho costeiro sujeito à influência de águas continentais.

As anomalias positivas de Eu nos sedimentos marinhos ou na água do mar têm sido atribuídas a processos de influxos hidrotermais acompanhados de enriquecimento em ETRL (e.g. Michard et al. 1983, Tlig 1987), comuns em sedimentos arqueanos, quando os mares primitivos recebiam forte contribuição de fluidos hidrotermais. Nos mares recentes isso é observado ao longo das cadeias meso-oceânicas e nos centros de expansão em bacias de retroarco, em ambiente redutor com temperaturas 
$>300^{\circ} \mathrm{C}$ e pH entre 2 e 4 (Fouquet el al. 1993 in Bau \& Moller 1993). A anomalia negativa de Eu é considerada característica de ambiente redutor em que $\mathrm{Eu}^{3+}$ é reduzido para $\mathrm{Eu}^{2+}$, embora alguns autores tenham sugerido que processos metamórficos ou metassomáticos possam gerar esta redução (e.g. Jarvis et al. 1975 in Fleet 1984). Para Morteani et al. (1983) anomalias negativas de $\mathrm{Eu}$ em carbonatos são encontradas em minerais formados a partir de soluções com baixo valor em Eh, enquanto as positivas são atribuídas a minerais formados por fluidos com alta fugacidade de oxigênio que interagiram na decomposição de feldspatos antes da formação dos carbonatos. Entretanto, as condições físico-químicas durante a migração dos fluidos parecem ser importantes para o desenvolvimento de anomalias de $\mathrm{Eu}$ (e.g. Bau 1991). Em seu estado divalente, Eu é menos absorvido (sob condições ácidas) durante a migração de fluidos do que os outros ETR trivalentes e, conseqüentemente, uma anomalia de Eu positiva pode se desenvolver. Isto é especialmente favorecido em ambientes de baixa fugacidade de oxigênio e temperaturas entre $200 \mathrm{e} 250^{\circ} \mathrm{C}$.

Os mármores estudados exibem padrão irregular caracterizado, sobretudo, por modesto enriquecimento em ETRL em relação aos ETRP e por anomalias fortemente positivas em Ce e ligeiramente positivas em Eu.

Considerando uma origem marinha para os carbonatos em questão, o enriquecimento em ETRL pode indicar (i) precipitação de carbonatos a partir de fonte aquosa diferente da água do mar; (ii) contaminação indireta das amostras por material enriquecido em ETRL e com anomalias positivas em Ce. Admitindo que os ETRL, em ambiente sedimentar, estão relacionados preferencialmente a partículas e colóides associados a matéria orgânica e a hidróxidos de Fe e Mn em ambiente estuarino, isso pode indicar incursão de material coloidal rico em hidróxido de Fe-Mn de estuário em carbonatos de ambiente marinho costeiro empobrecido em ETRL. A influência é corroborada também pelo ligeiro enriquecimento em elementos terras raras intermediários, particularmente em Eu, que mostra modesta anomalia positiva. A presença de uma forte concentração silicosa, bem como a anomalia positiva de Ce nos mámores dolomíticos estudados, pode corroborar também o influxo de águas continentais ao seio da bacia em fase de evaporação e não a um influxo hidrotermal. Tudo isso sugere que o conjunto de carbonatos estudado se desenvolveu em sistema marinho raso, submetido à influência de águas estuarinas.

\section{QUÍMICA ISOTÓPICA}

Amostragem e Procedimentos Analíticos Vinte e quatro amostras dos mármores calcítico-dolomíticos foram analisadas com vistas a determinações isotópicas de $\mathrm{C}$ e $\mathrm{O}$ no Laboratório de Isótopos Estáveis (LABISE) da Universidade Federal de Pernambuco. As amostras (10 a $20 \mathrm{mg}$ ) foram dissolvidas com ácido fosfórico a $100 \%$ e a $25^{\circ} \mathrm{C}$. O CO liberado dessa reação, após ser criogenicamente purificado (armadilha com nitrogênio líquido + álcool para remover a água resultante da reação do carbonato com ácido fosfórico), foi analisado em espectrômetro de massa de fonte gasosa (SIRA II) de dupla admissão, triplo coletor, usando o gás de referência BSC (Borborema skarn calcite), calibrado segundo padrões internacionais (NBS-18, NBS-19, NBS-20). Os valores de $\delta^{13} \mathrm{C}$ e $\delta^{18} \mathrm{O}$ dos carbonatos analisados, tendo como referência os padrões PDB para Carbono e SMOW para Oxigênio, são apresentados na Tabela 3.

Avaliação da qualidade das amostras A composição isotópica de uma rocha carbonática pode ser modificada por vários processos de alteração, incluindo processos sin-sedimentares, como os biológicos nos quais o metabolismo microbiológico da matéria orgânica produz produtos de composição isotópica dife- rente e os processos pós-formacionais, entre os quais metamorfismo, hidrotermalismo, carstificação e/ou alterações meteóricas que levam em geral à descarbonatação.

Objetivando determinar as possíveis modificações pós-formacionais introduzidas por alterações meteóricas foram feitos alguns testes petrográficos e geoquímicos, entre estes aqueles que se baseiam nas concentrações de Mn e Sr. Nesse sentido, a razão $\mathrm{Mn} / \mathrm{Sr}$ é bastante útil. Sob a influência de fluidos meteóricos $\mathrm{Sr}$ é expelido dos carbonatos marinhos, enquanto o Mn é incorporado. Para Kaufman et al. (1992) análises com boa qualidade possuem razões $\mathrm{Mn} / \mathrm{Sr}<3$ e razões $\mathrm{Mn} / \mathrm{Sr}<10$ em carbonatos (calcário ou dolomito) podem reter os valores de $\delta^{13} \mathrm{C}$ primários. As razões $\mathrm{Mn} / \mathrm{Sr}$ dos mármores estudados (Tabela 1) são inferiores a 3, com exceção das amostras PT-35A e PT-35B (3,09 e 3,22, respectivamente). 18 amostras apresentam valores inferiores a 1, indicando boa confiabilidade dos resultados obtidos nas amostras analisadas que podem preservar ainda os valores de $\delta^{13} \mathrm{C}$ primários.

DISCUSSÃO Das 24 amostras analisadas, 23 apresentam valores de $\delta^{13} \mathrm{C}$ relativamente homogêneos, oscilando entre $+1,7$ e $-0,1 \%$. Uma amostra exibe valor excepcionalmente baixo ( $-7,6 \%$ ). Os valores de $\delta^{18} \mathrm{O}_{\text {SMOw }}$ variam entre $+18.3 \mathrm{e}+25 \%$, excepcionalmente, atingindo valor de $+27,2 \%$ ( $\left.\mathrm{PT}-37^{\prime} \mathrm{B}\right)$. O diagrama $\delta^{13} \mathrm{C}$ versus $\delta^{18} \mathrm{O}_{\text {SMOW }}$ (Fig. 15) mostra a ocorrência de relativa correlação positiva entre as amostras. A amostra PT$37^{\prime} \mathrm{B}$ está em desequilíbrio com as demais, o que pode ser explicado pelo fato de provir de área próxima às brechas de dissolução cárstica recentes, indicando que foi afetada ou modificada por processos de carstificação relacionados ao intemperismo. Os mármores calcítico-dolomíticos $\left(\delta^{13} \mathrm{C}_{\mathrm{PDB} \%}\right.$ entre $+1,7$ e $\left.-0,1 \%\right)$ situar-se-iam, portanto, no domínio de um ambiente salobro ou marinho confinado com fortes influências continentais.

Os valores de $\delta^{18} \mathrm{O}_{\text {SMOW }}$ entre +18.3 e $+27,2 \%$ são compatíveis com carbonatos marinhos pré-cambrianos metamorfisados (+12 a $+28 \%$, Borsthevsky 1981 in Qiusheng 1988). Para Melezhik et al. (1999) os carbonatos ou, mais precisamente, os dolomitos de ambientes marinhos normais de diferentes idades, têm valores de $\delta^{13} \mathrm{C}=0 \pm 2 \%$ e de $\delta^{18} \mathrm{O}_{\text {SMOw }} \sim 28 \%$.

Estes fatos indicam que as amostras estudadas, mesmo afetadas por processos pós-formacionais, tais como metamorfismo de fácies anfibolito, ainda conservam, ao menos em parte, os valores de $\delta^{18} \mathrm{O}_{\text {SMow }}$ e de $\delta^{13} \mathrm{C}$ indicadores de seu ambiente de formação. Segundo Hoefs (1997), os mármores, em particular, são relativamente impermeáveis durante o metamorfismo e podem atuar como barreiras ao fluxo dos fluidos, limitando a escala de homogeneização e favorecendo a canalização dos fluidos junto às camadas de silicatos. Mármores maciços, por exemplo, podem preservar sua assinatura sedimentar mesmo em fácies de alto grau metamórfico (Valley 1990 in Hoefs 1997).

Os processos de carstificação, entretanto, parecem ter introduzido forte variação isotópica nestas rochas, resultando em valores de $\delta^{13} \mathrm{C}$ e $\delta^{18} \mathrm{O}_{\mathrm{SMOw}}$ excepcionalmente baixos e altos, respectivamente $\left(\mathrm{PT}-37 \mathrm{~B} \delta^{13} \mathrm{C}-7,6 \% ; \quad \delta^{18} \mathrm{O}_{\text {SMOW }}-+27,2 \%\right.$ ). Isso assinala que os isótopos de carbono durante a carstificação indicam o ambiente em que a rocha se redepositou (dissolução e reprecipitação por águas continentais), enquanto os isótopos de oxigênio são inalterados, preservando os valores das rochas originais ou mesmo ligeiramente mais pesado, resultado de uma maior concentração de oxigênio 18 proveniente das águas que dissolveram o carbonato original. Considerando essas observações, pode-se dizer que o oxigênio é mais facilmente afetado por fluidos intersticiais em elevada temperatura, por exemplo durante o metamorfismo, do que com fluidos meteóricos de baixa temperatura.

Os isótopos de $\mathrm{C}$ têm sido utilizados também como uma fer- 
Tabela 3. Caracterização mineralogógica e isotópica de amostras de mármore da Seqüência de Acarape. cc-calcita; dol-dolomita; trem - tremolita; diop - diopsídio; carb - carbonato; qzo - quartzo; flog - flogopita.

\begin{tabular}{|c|c|c|c|c|c|}
\hline & Amostra & Associação Mineralógica & $\delta \mathrm{O}^{18} \mathrm{SMOW}$ & $\delta \mathrm{O}^{18} \mathrm{PDB}$ & $\delta \mathrm{C}^{13} \mathrm{PDB}$ \\
\hline 1 & PT $34 \mathrm{~A}$ & cc $(54 \%)$, dol (24\%), diop (13\%), trem (8\%) & 24,0 & $-6,6$ & 1,2 \\
\hline 2 & PT .34 B & cc $(37 \%)$, dol (36\%), diop (22\%), trem (4\%) & 21,1 & $-9,4$ & 1,3 \\
\hline 3 & PT .34 C & $\operatorname{cc}(67 \%)$, dol $(29 \%), \operatorname{trem}(4 \%)$ & 24,4 & $-6,2$ & 1,2 \\
\hline 4 & PT .34 D & $\operatorname{cc}(71 \%)$, dol (25\%), diop (2\%), trem (2\%), qzo & 24,1 & $-6,5$ & $+1,3$ \\
\hline 5 & PT .34 E & $\begin{array}{c}\operatorname{cc}(31 \%), \text { dol }(10 \%), \text { diop (traços), trem (38\%), qzo } \\
(20 \%)\end{array}$ & 23,8 & $-6,8$ & 1,7 \\
\hline 6 & PT .34 F & cc $(71 \%)$, dol $(20 \%)$, diop ( traços ), trem $(9 \%)$ & 24,9 & $-5,7$ & 1,6 \\
\hline 7 & PT .34 G & cc $(59 \%)$, dol (22\%), diop (3\%), trem (14\%), qzo & 22,4 & $-8,1$ & 1,3 \\
\hline 8 & PT $.34 \mathrm{H}$ & cc $(67 \%)$, dol $(20 \%), \underset{(6 \%)}{\text { diop }}(5 \%)$, trem $(2 \%)$, qzo & 22,8 & $-7,8$ & 1,5 \\
\hline 9 & PT .34 I & cc $(68 \%)$, dol (25\%), diop (traços), trem (7\%) & 23,2 & $-7,3$ & 1,6 \\
\hline 10 & PT .34 J & cc $(73 \%)$, dol $(25 \%)$, trem $(2 \%)$ & 22,8 & $-7,7$ & 1,4 \\
\hline 11 & PT $.34 \mathrm{~K}$ & cc $(65 \%)$, dol $(25 \%)$, trem $(10 \%)$, diop (traços) & 23,2 & $-7,4$ & 1,5 \\
\hline 12 & PT .34 L & $\operatorname{cc}(70 \%)$, dol $(25 \%)$, trem $(4 \%)$ & 23,5 & $-7,1$ & 1,6 \\
\hline 13 & PT .34 M & cc $(66 \%)$, dol $(29 \%)$, trem $(5 \%)$ & 22,8 & $-7,7$ & 1,4 \\
\hline 14 & PT .34 N & $\operatorname{cc}(61 \%), \operatorname{dol}(23 \%)$, trem $(7 \%), \operatorname{diop}(9 \%)$ & 22,5 & $-8,1$ & 1,7 \\
\hline 15 & PT .34 O & cc $(54 \%)$, dol (32\%), trem (14\%) & 18,8 & $-11,6$ & 1,0 \\
\hline 16 & PT . 34 A' & qzo (87\%), cc (7\%), diop (3\%), trem (4\%) & 22,1 & $-8,4$ & 1,1 \\
\hline 17 & PT .37'A & $\operatorname{cc}(71 \%)$, dol $(25 \%)$, trem $(3 \%)$ & 22,3 & $-8,3$ & 1,2 \\
\hline 18 & PT .37’ B & $\begin{array}{l}\text { qzo }(80 \%) \text {. Outros minerais }(20 \%) \text { : carb }(70 \%) \text {, diop } \\
(3 \%) \text {, trem }(15 \%) \text {, qzo }(10 \%) \text {, mineral opaco ferroso } \\
(2 \%)\end{array}$ & 27,2 & $-3,5$ & $-7,6$ \\
\hline 19 & PT .35A & cc $(47 \%)$, dol (34\%), trem $(19 \%)$ & 19,4 & $-11,0$ & 0,5 \\
\hline 20 & PT .35 B & & 19,3 & $-11,2$ & 0,8 \\
\hline 21 & PT .23 C & $\operatorname{cc}(59 \%)$, dol $(23 \%)$, trem $(18 \%)$ & 20,9 & $-9,6$ & 0,9 \\
\hline 22 & PT . 43 D1 & cc $(55 \%)$, dol (32\%), trem (5\%), flog (7\%) & 18,3 & $-12,1$ & $-0,9$ \\
\hline 23 & PT .43 D2 & carb (2\%), diop (5\%), trem (93\%) & 19,3 & $-11,2$ & $-0,1$ \\
\hline 24 & PT .22 B & $\operatorname{carb}(99 \%)$, trem $(1 \%)$ & 19,2 & $-11,2$ & 0,8 \\
\hline
\end{tabular}




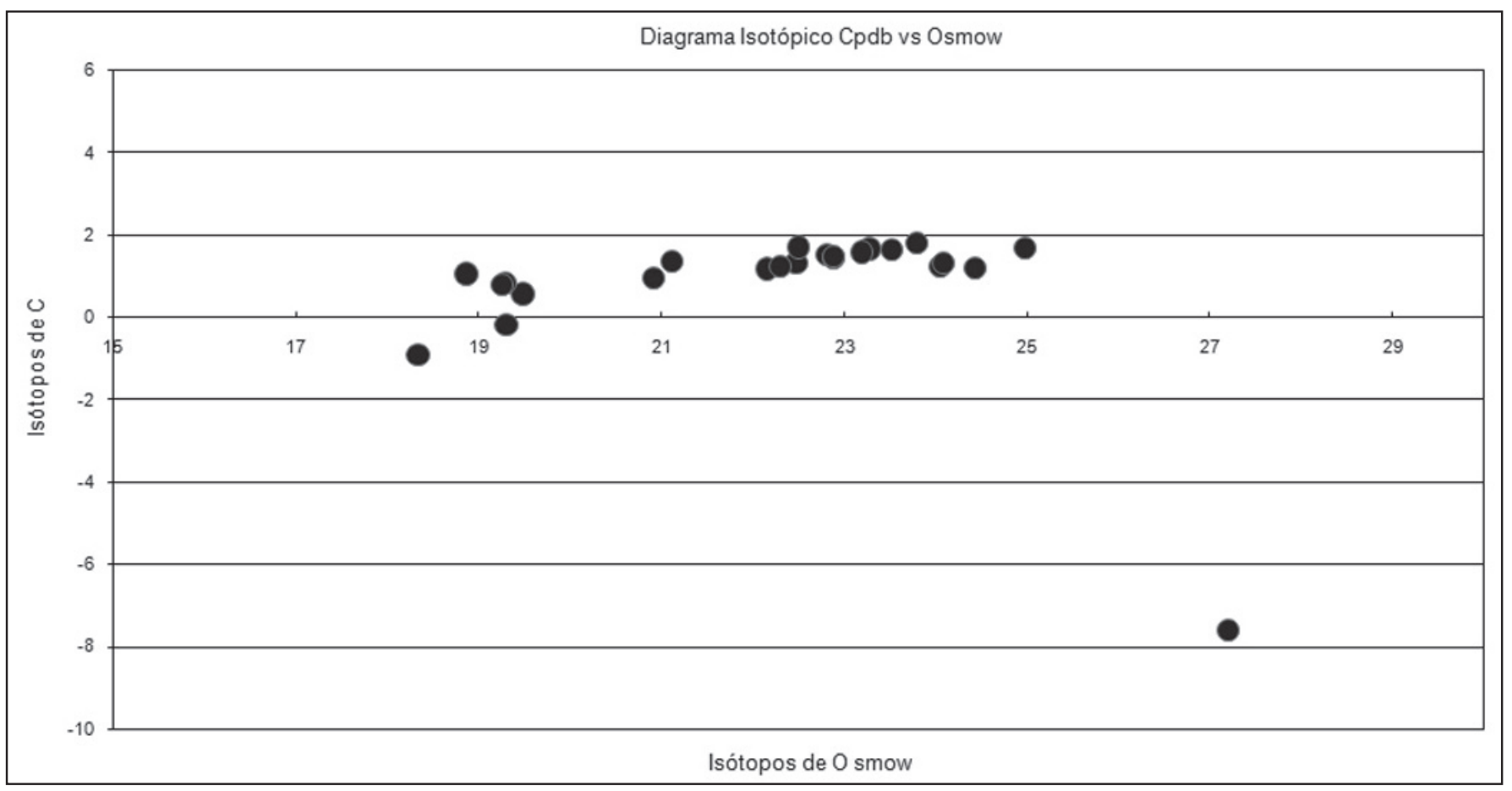

Figura 15 - Diagrama $\delta^{13} \mathrm{C}_{\mathrm{PDB}}$ versus $\delta^{18} \mathrm{O}_{\mathrm{SMO}}$ para os mármores estudados.

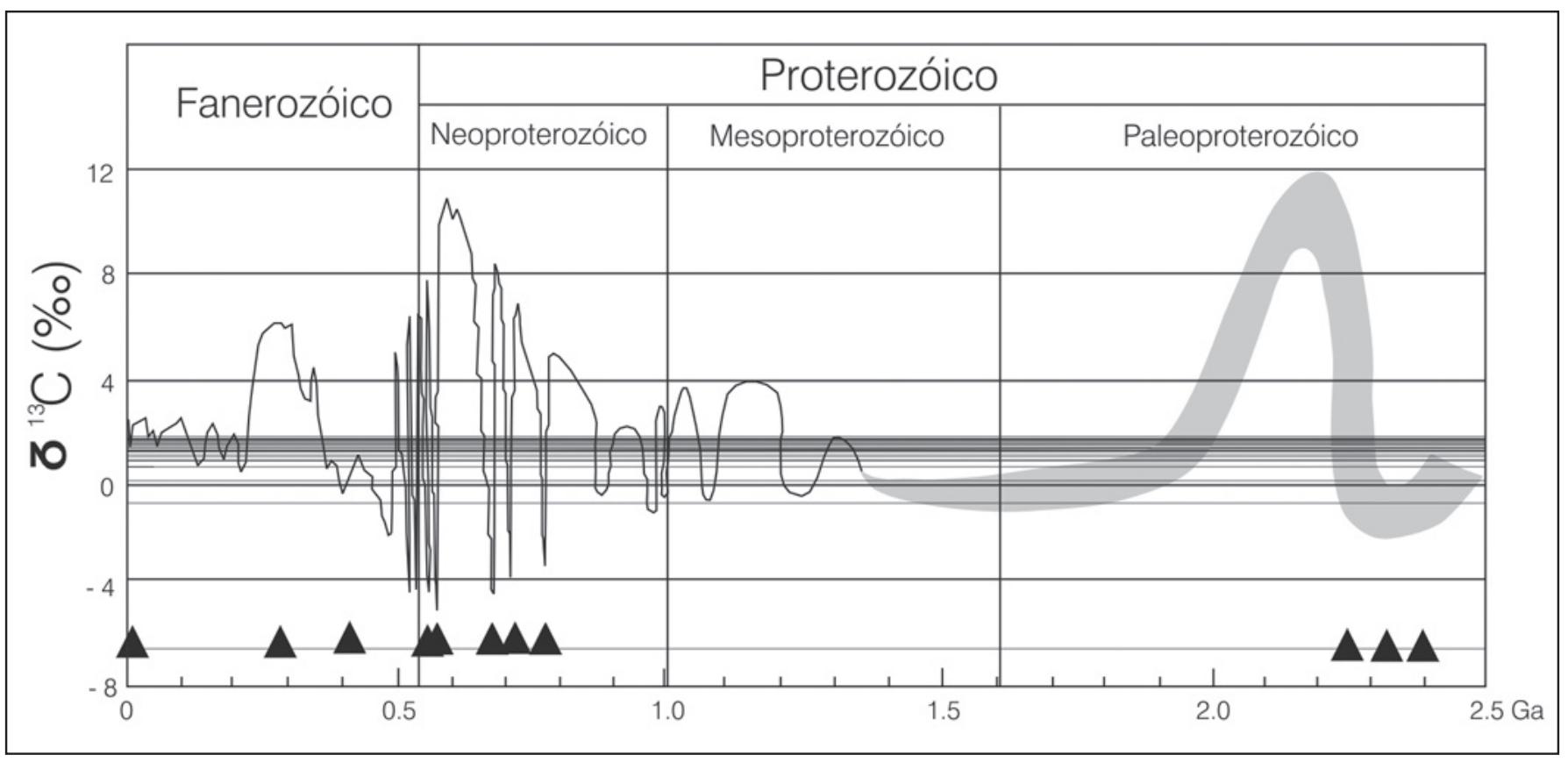

Figura 16 - Curva de variação $\delta^{13}$ C no decorrer do Proterozóico e Fanerozóico (reproduzida de Hoffman et al. 1998, Kaufman \& Knoll 1995; Kah et al. 1999, Sial et al. 2000). Os triângulos indicam eventos glaciais.

ramenta importante na estratigrafia do Pré-Cambriano, especialmente quando os sedimentos são afossilíferos (Kaufman 1998, Melezhik et al. 1999, Sial et al. 2000). Segundo esses autores, variações temporais em $\delta^{13} \mathrm{C}$ são interpretadas como variações seculares na razão fluxo carbônico reduzido/ carbono inorgânico oxidado como produto de mudanças na taxa relativa de soterramento de carbono inorgânico e orgânico no ciclo sedimentar.

Hoffman et al. (1998), Kah et al. (1999) e Sial et al. (2000) compilaram as curvas de variação secular de $\delta^{13} \mathrm{C}$ em carbonatos marinhos a partir de $2.5 \mathrm{Ga}$ (Fig.16). Nota-se uma forte anomalia positiva de $\delta^{13} \mathrm{C}$ no intervalo 2,33 a 2,06 Ga (evento Lomagundi), enquanto o restante do Paleoproterozóico (2,0 a 1,6 Ga) e a maior parte do Mesoproterozóico apresentam valores de $\delta^{13} \mathrm{C}$ próximos a $0 \% \%_{\mathrm{PDB}}$, com ligeiros valores positivos entre 1,1 . e 1,0 Ga. No Neoproterozóico verifica-se a alternância de fortes excursões positivas com excursões negativas, onde cada pulso negativo está associado a eventos glaciais.

A plotagem dos dados das amostras estudadas junto a essas curvas de variação (Figura 16) sugere que se trata de carbonatos desenvolvidos no início do Neoproterozóico. 
CONCLUSÕES Os mármores da Seqüência Acarape apresentam composição entre calcítica-dolomítica e dolomítica, com discretas variações mineralógicas no campo das rochas calcissilicáticas, refletidas nos diagramas de elementos maiores. Parte das amostras que plotam no campo das rochas calcissilicáticas corresponde a mármores silicosos empobrecidos em $\mathrm{Al}_{2} \mathrm{O}_{3}(<1 \%), \mathrm{Na}_{2} \mathrm{O}(<0.1 \%)$ e $\mathrm{K}_{2} \mathrm{O}(<0,04 \%)$, incompatível para rochas calcissilicáticas que, em geral, contêm percentuais importantes desses componentes químicos, que resultam em mineralogia muito mais complexa.

Os nódulos de sílica encontrados junto aos mármores são de origem diagenética, tendo crescidos a partir de um substrato contendo sulfato e dolomita. A presença de moldes de sulfatos e pequenos cristais de dolomita inclusos nos cristais de quartzo corroboram a origem diagenética.

A fonte da sílica é dominantemente inorgânica e resulta da dissolução de quartzo detrítico presente na lama carbonática sob influência evaporítica. A evaporação favoreceria a precipitação de sulfato que induziria a dissolução de quartzo devido ao aumento do $\mathrm{pH}$. Subseqüentes flutuações geoquímicas no ambiente de sedimentação, marcadas pela diminuição do $\mathrm{pH}$, provocaram a dissolução do sulfato e a precipitação de quartzo que, posteriormente, foi deformado. A diminuição do $\mathrm{pH}$ pode ter sido induzida por mistura de águas doces, portadoras de sílica, com águas marinhas. Isso favoreceu a precipitação de sílica ao longo dos planos de estratificação ou outros canais de permeabilidade. Pode-se admitir também reações bioquímicas nas quais os sulfatos são reduzidos por atividades bacterianas, o que pode elevar a produção dos ácidos orgânicos junto com os de $\mathrm{H}_{2} \mathrm{~S}$ e $\mathrm{CO}_{2}$, fazendo baixar o $\mathrm{pH}$. Tudo isso indica uma paleogeografia do tipo sistema marinho raso, submetido à influência de águas estuarinas.

Os elementos terras raras mostram padrão irregular, caracterizado por modesto enriquecimento das terras raras leves em relação às terras raras pesadas e por anomalia fortemente positiva de Ce e ligeiramente positiva de Eu. A provável incursão de material coloidal, de estuário, rico em hidróxido de $\mathrm{Fe}$, no qual os elementos terras raras leves possuem preferência, em carbonatos de ambiente marinho costeiro empobrecido em LREE, poderia explicar a presença mais acentuada de ferro nas amostras dos grupos $2 \mathrm{e}$, em parte, nas do grupo 3.

Os valores de $\delta^{13} \mathrm{C}$ e $\delta^{18} \mathrm{O}$ dos metacarbonatos indicam formação a partir de complexa combinação de ambientes marinho raso e marinho confinado evaporítico (sabkha), sujeito a influências continentais e que foram, em parte, modificados durante os eventos metamórficos. As modificações foram, entretanto, localizadas, e incapazes de apagar os registros sedimentares.

Os valores de $\delta^{13} \mathrm{C}_{\mathrm{PDB}}$ de $0 \pm 2 \%$ dos níveis metacarbonáticos melhor preservados sugerem que se trata de carbonatos depositados no início do Neoproterozóico.

Agradecimentos Os autores agradecem à CAPES, através do PROCAD, Proc. 0083/01-1, pela ajuda financeira ao desenvolvimento da pesquisa e aos comentários do revisor anônimo que permitiram aperfeiçoar o trabalho.

\section{Referências}

Bau M. 1991. Rare earth element mobility during hydrothermal and metamorphic fluid-rock interaction and the significance of the oxidation state of europium. Chem. Geol., 93:219-230.

Bau M. \& Möller P. 1993. Rare earth element systematics of the chemically precipitated component in Early Precambrian iron formations and the evolution of the terrestrial atmosphere-hydrospherelithosphere system. Geochimica et Cosmochimica Acta, 57:2239-2249.

Bucher K. \& Frey M. 1994. Petrogenesis of Metamorphic Rocks. Springer, Berlin, 318p.

Chafetz H.S. \& Zhang J. 1998. Authigenic euhedral megaquartz crystals in a Quaternary dolomite. J. Sedimentary Research, 68(5):9941000 .

Dana J. D. 1983. Manual de Mineralogia. Universidade de São Paulo, São Paulo, 642p.

Elderfield H. 1988. The oceanic chemistry of the rare-earth elements. Phylosophical Transactions of the Royal Society London, 325:105106.

Elderfield H \& Graves M. 1982. The rare earth elements in seawater. Nature, 296(18):214-219.

Deer W.A., Howie R.A., Zussman J. 1962. Rock forming minerals: Non silicates. Logmans, London, v. 5, 371p.

Evensen N.M., Hamilton J.P., Onions R.K. 1978. Rare-earth abundance in chondritic meteorites: Geochim. Cosmochim. Acta, 31:16371665.

Fleet A.J. 1984. Aqueous and sedimentary geochemistry of the rare earth elements. In: P. Henderson \& W.S. Fyfe (eds.) Rare Earth Element Geochemistry. New York, Elsevier, pp.:343-373.

Friedman G.M. 1997. Dissolution-collapse breccias and paleokarst resulting from dissolution of evaporate rocks, especially sulfates. Carbonates and Evaporites, 12(1):53-63.

Friedman G.M. \& Radke B. 1979. Evidence for sabkha overprint and conditions of intermittent emergence in Cambrian-Ordovician carbonates of northeastern North America ad Queensland, Australia: Northeastern Geology, 1:18-42.

Friedman G.M. \& Shukla V. 1980. Significance of authigenic quartz euhedra after sulfates: example from the Lockporth Formation (Middle
Silurian ) of New York. Jour. Sedimentary Petrology, 50(4):12991304.

Haskin L.A., Haskin M.A., Frey F.A., Wildman T.R. 1968. Relative and absolute terrestrial abundances of the rare earths. In: L.H. Ahrens (ed.) Origin and distribution of the elements, Oxford, Pergamon, v.1, pp.: 889-911.

Holser W.T. 1997. Evaluation of the application of rare-earth elements to paleoceanography. Palaeogeography, Palaeoclimatology,Palae oecology., 132:309-323.

Hoefs J. 1997. Stable Isotope Geochemistry. Springer-Verlag, 201p.

Hoffman P.F., Kaufman A.J., Halverson G.P. 1998. Comings and goings global glaciations on a Neoproterozoic tropical platform in Namibia. GSA Today, 8(5):1-10.

Kah L.C., Sherman A.G., Narbonne G.M., Knoll A.H., Kaufman A..J. 1999. ${ }^{\text {тм}} 13 \mathrm{C}$ Stratigraphy of the Proterozoic Bylot Supergroup, Baffin Islands, Canada: implications for lithostratigraphy correlations. Can. Jour. Earth Sci., 36:313-332.

Kaufman A.J. 1998. Neoproterozoic chemostratigraphy: key events inEarth history ordered by detailed intra- and inter-basinal correlation. In: SBG, Congr. Bras. Geol., 40, Belo Horizonte, Boletim de Resumos, p. 2.

Kaufman A.J., Jacobsen S.B., Knoll A.H. 1992. Biostratigraphic and chemostratigraphic correlation of Neoproterozoic sedimentary successions: Upper Tindir Group, northwestern Canada, as a test case. Geology, 20:181-185.

Kaufman A.J., Knoll A.H. 1995. Neoproterozoic variations in the Cisotopic composition of seawater: stratigrafic and biogeochemical implications. Precambrian Research, 73:27-49.

Knauth I.P.1979. A model for the origin of chert in limestone: Geology, 7:274-277.

Krauskopf K.B. 1956. Dissolution and Precipitation of Silica at Low Temperature. Geochim. et Cosmochim. Acta, 10(1):1-26.

Krauskopf K.B. 1959. The Geochemistry of Silica in Sedimentary Environments. Soc. Econ. Paleontologists and Mineralogists, Spec. Pub., 7:4-19.

Maliva R.G \& Siever R. 1989. Nodular chert formation in carbonate ro- 
cks: Journal of Geology, 97:76-85.

Mclane M. 1995. Sedimentology. Oxford University Press, New York, $423 \mathrm{p}$.

Mclennant S.M., Freyer B.J., Young G.M. 1979. The geochemistry of the carbonate rich Espanhola Formation (Huronian) with emphasis on the rare earth elements. Can. J. Earth Sci. 16:230-239.

Michard A., Albarède F., Michard G., Minster J.F., Charlou J.L. 1983. Rare earth elements and uranium in high temperature solutions from the East Pacific Rise hydrothermal vent fields $\left(13^{\circ} \mathrm{N}\right)$. Nature, 303:795-797.

Melezhik V.A., Fallick A.E., Medvedev P.V., Makarikhin V.V. 1999. Extreme ${ }^{13}$ Carbon enrichment in ca. 2.0 Ga magnesite-stromatolitedolomite-"red beds" association in a global context: a case for the world-wide signal enhanced by a local environement. Earth-Science Reviews, 48:71-120.

Morteani G., Schley F., Möller P. 1983. On the formation of magnesite. In: H.J. Schneider (ed.) Mineral Deposits of the Alps and of the Alpine Epoch in Europe. Berlin Heidelberg, Springer-V. pp.:105-116.

Nothdurft L. D., Webb G.E., Kamber B.S. 2004. Rare earth element geochemistry of Late Devonian reefal carbonates, Canning Basin, Western Australia: Confirmation of a seawater REE proxy in ancient limestones. Geochim. Cosmochim. Acta, 68(2):263-283.

Parente C.V., Guillou J.J., Barbosa H.S. 1996. Evaporitos pré-cambrianos ( 1,8Ga) da Faixa Orós, Ceará (Brasil). Revista de Geologia, 9:5-16.

Piper D.Z. 1974. Rare earth elements in the sedimentary cycle: summary. Chemical Geology, 14:285-304.

Pollock S.G.1987. Chert formation in an Ordovician volcanic arc. J.Sediment. Petrology. 57:75-87.

Qiusheng Z. 1988. Early Proterozoic tectonic styles and associated mineral deposits of the north China Platform. Precambrian Research, 39:1-29.

Sial A .N., Ferreira V.P., Almeida A .R., Romano A .W., Parente C.V.,
Costa M.L., Santos V.H. 2000. Carbon isotope fluctuations in Precambrian carbonate sequences of several localities in Brazil. Anais da Academia Brasileira de Ciências, 72(4):539-558.

Tlig S. 1987. The Sr and rare earth element (REE) behaviour during diagenesis of limestone in various environmental conditions. In: R.W. Hurst, T.E. Davis, S.S. Augustithis (eds.) The pratical applications of trace elements and isotopes to environmental biochemistry and mineral resources evaluation. Athens, Greece, Theophrastus Publications, pp.: 103-147.

Torres P.F.M. 2004. Aspectos geológicos e geocronológicos da região de Redenção (CE) e adjacências - Contexto regional e evolutivo: Seqüencia Acarape e Suite Pacatuba. Dissertação de Mestrado, Departamento de Geologia, UFC, 199p.

Torres P.F.M., Parente C.V., Dantas E.L., Arthaud M.H., Fuck R.A., Castro D.L. 2005. Aspectos geológicos e geocronólogicos da Sequiência Metavulcano-Sedimentar Acarape, CE. Revista de Geologia (no prelo).

Tucker M.E. 1991. Sedimentary Petrology. An introduction to the origin of sedimentary rocks. $2^{\mathrm{a}} \mathrm{Ed}$, Backwell Science, $260 \mathrm{p}$.

Van Kranendonk M.J., Webb G.E., Kamber B.S. 2003. Geological and trace element evidence for a marine sedimentary environment of deposition and biogenicity of $3.45 \mathrm{Ga}$ stromatolitic carbonates in the Pilbara Craton, and support for a reducing Archaean ocean. Geobio$\log y$, 1:91-108.

Wilde P., Quinby-Hunt M.S., Erdtman B.D. 1996. The whole-rock cerium anomaly: a potencial indicator of eustatic sea-level changes in shales of the anoxic facies. Sedimentary Geology, 101:43-53

Manuscrito A1643 Aprovado em 30 de outubro de 2006 